\title{
HIV: MECANISMO DE REPLICAÇÃO, ALVOS FARMACOLÓGICOS E INIBIÇÃO POR PRODUTOS DERIVADOS DE PLANTAS
}

\section{Roberta Costa Santos Ferreira}

Instituto de Ciências Biológicas e da Saúde, Universidade Federal de Alagoas, Praça Afrânio Jorge, s/n, 57010-220 Maceió - AL, Brasil Alessandro Riffel

Embrapa Tabuleiros Costeiros - UEP/Alagoas, CP 2013, 57061-970 Maceió - AL, Brasil

Antônio Euzébio Goulart Sant'Ana*

Instituto de Química e Biotecnologia, Universidade Federal de Alagoas, Cidade Universitária, 57072-970 Maceió - AL, Brasil

Recebido em 14/8/09; aceito em 5/4/10; publicado na web em 9/8/10

\begin{abstract}
HIV: REPLICATION MECHANISM, PHARMACOLOGICAL TARGETS AND INHIBITION BY PRODUCTS DERIVED FROM PLANTS. The AIDS epidemy has spread out and led to the diversification on the research for new antiviral drugs. Natural products, especially those derived from plants, are well-recognized as excellent sources of new drugs. Several of them have inhibitory activity against HIV replication, and some have been already clinically tested, with favorable results. This review presents the biochemical basis of the viral cycle and the research up to date on the identification, determination of the mechanism of biological action together with the therapeutical potential of plants-derived natural products, in the inhibition of HIV.
\end{abstract}

Keywords: HIV; natural products; antiviral.

\section{INTRODUÇÃO}

O vírus da imunodeficiência humana (HIV), pertencente à família Retroviridae, gênero Lentivirus, produz a base patológica da síndrome da imunodeficiência adquirida (AIDS) ${ }^{1,2}$ que permanece como um problema de saúde mundial de dimensões sem precedentes. Conhecido há pouco mais de 27 anos, o HIV já causou cerca de 25 milhões de mortes no mundo. ${ }^{3}$ Só no Brasil, desde 1990, o número de óbitos gira em torno de 11 mil por ano. ${ }^{4}$

Toda esta morbi-mortalidade estimulou o desenvolvimento de terapias antirretrovirais. ${ }^{5}$ Durante a década passada, tivemos um marcante crescimento no desenvolvimento de fármacos para combater a infecção causada pelo HIV. O manejo terapêutico desta infecção consiste principalmente no uso de inibidores específicos do ciclo de replicação viral $^{6,7}$ que, quando administrados em conjunto, reduzem efetivamente, por um longo período, a carga viral a níveis indetectáveis. ${ }^{8,9}$

Entretanto, apesar da alta potência que os medicamentos atuais oferecem, a falência terapêutica também ocorre. ${ }^{5}$ Essa falência é consequência da persistência e alta mutagenicidade do HIV, associadas ao uso de antivirais por um período prolongado. ${ }^{8,10}$

Além disso, os medicamentos atualmente em uso nem sempre são bem tolerados e exibem uma série de efeitos adversos, ${ }^{11}$ reduzindo assim, a aderência e a continuidade do regime terapêutico complexo. Por estas razões é real a necessidade de identificação e desenvolvimento de novas substâncias que atuem em diferentes etapas do ciclo de replicação viral e que possam ser usadas em substituição ou em combinação com os antivirais em uso corrente. ${ }^{5,8,12}$

Neste contexto, alguns grupos vêm realizando trabalhos com produtos naturais, especialmente os derivados de plantas, mostrando que muitos apresentam atividade inibitória da replicação do HIV ${ }^{13-15}$ como o ácido platânico (1) e o betulínico (2), ${ }^{16}$ cujo derivado, bevirimato (3), ${ }^{17}$ se encontra em testes clínicos, com resultados favoráveis, assim como calanolídeo A (4), ${ }^{18-20}$ hipericina (5) ${ }^{21}$ e prostratina (6).$^{18}$

Nos últimos anos, várias pesquisas foram realizadas com contribuições relevantes sobre os aspectos fitoquímicos e atividades bioló-

*e-mail: aegs@qui.ufal.br

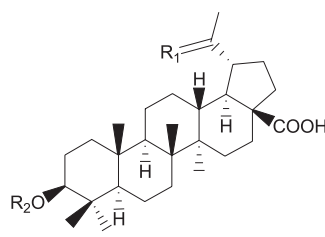

(1) Ác. platânico: $\mathrm{R}_{1}=\mathrm{O}, \mathrm{R}_{2}=\mathrm{H}$ (2) Ác. betulínico: $\mathrm{R}_{1}=\mathrm{CH}_{2}, \mathrm{R}_{2}=\mathrm{H}$ (3) Bevirimato: $\mathrm{R}_{1}=\mathrm{CH}_{2}$

$\mathrm{R}_{2}=$ $\underset{\mathrm{HOOC}}{\mathrm{R}_{2}=}>\mathrm{CO}$

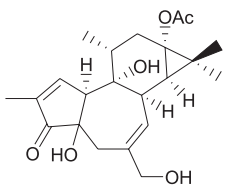

(6) Prostratina

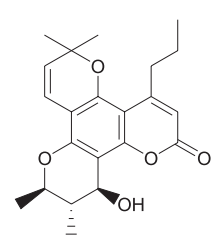

(4) Calanolideo A

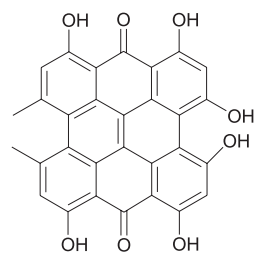

(5) Hipericina 
tem crescido muito, o que podemos observar pelo grande número de publicações de pesquisas e revisões acerca do tema. Entretanto, para o desenvolvimento de novos antirretrovirais é de suma importância o conhecimento detalhado do ciclo de replicação do HIV e dos possíveis alvos de atuação dos inibidores. Desta forma, neste trabalho são discutidas as bases bioquímicas do ciclo viral e o corrente estado das pesquisas de identificação e determinação do mecanismo de ação antiviral das principais plantas investigadas até o momento.

\section{ASPECTOS GERAIS DO HIV}

Os vírus da AIDS humana não são homogêneos, porém a maioria consiste em variantes do HIV-1. Um segundo vírus, o HIV-2, parece prevalecer apenas na África Ocidental, e é muito menos virulento. A similaridade entre as sequências genômicas do HIV-1 e do HIV-2 é de apenas $40 \% .^{24}$

Os vírions (partículas virais completas) do gênero Lentivirus medem entre 80 e $100 \mathrm{~nm}$ de diâmetro, possuem envelope lipoproteico ligeiramente esférico, capsídeo cilíndrico e genoma formado por duas fitas simples sense de RNA linear. O genoma do HIV é mais complexo que dos retrovírus oncogênicos, contendo alguns genes de replicação adicionais. ${ }^{24}$

O HIV possui os três genes estruturais gag, env e pol comuns aos retrovírus, e ainda, os genes regulatórios tat, rev e nef, e os genes acessórios vif, vpr e $v p u$ (no HIV-1) ou $v p x$ (no HIV-2) ${ }^{24,25}$ Os genes estruturais codificam as poliproteínas Gag, Env e Pol, que são subsequentemente clivadas pelas proteases virais em proteínas individuais. As quatro proteínas Gag, MA (matriz, p17), CA (capsídio, p24), NC (nucleocapsídio, p7) e p6, e as duas glicoproteínas Env, SU (superfície, gp120) e TM (transmembrana, gp41), são componentes estruturais que formam o capsídeo e o envelope viral. ${ }^{1,25}$

As três proteínas Pol; PR (protease, p11), TR (transcriptase reversa, p66/p51) e IN (integrase, p32) provêem algumas funções enzimáticas essenciais e também são encapsuladas com a partícula viral. ${ }^{1,25}$

O HIV codifica ainda seis proteínas adicionais, das quais três (Vif, Vpr e Nef) são encontradas na partícula viral. A proteína Vif está associada à infectividade viral e ao controle da produção das partículas virais infecciosas, ${ }^{26}$ a Vpr contribui para o transporte do DNA pró-viral para o núcleo da célula infectada ${ }^{25}$ e a Nef ajuda a diminuir os níveis celulares de CD4, MHC classe $\mathrm{I}^{27}$ e MHC classe II..$^{25,28}$ As proteínas Tat e Rev estão envolvidas com a regulação da expressão gênica, ${ }^{25,26}$ e a proteína transmembrana Vpu diminui a expressão de CD4, MHC classe II e promove a liberação dos novos vírions. ${ }^{29}$

\section{REPLICAÇÃO DO HIV}

A característica mais marcante da infecção por HIV é a depleção seletiva de linfócitos CD4+, entretanto, este vírus também infecta monócitos, macrófagos, células de Langerhans, entre outras. ${ }^{1,30}$

A infecção pelo HIV começa com a etapa de adsorção, que compreende a ligação do vírion à superfície da célula alvo. Esta é mediada por uma interação de alta afinidade entre o domínio extracelular da glicoproteína viral gp120 e receptores celulares específicos, sendo o CD4 o principal receptor para HIV-1 e HIV-2. Entretanto, apenas a interação gp120-CD4 não é suficiente para a entrada do HIV na célula. Um grupo de receptores de quimiocinas (pertencentes à família de receptores acoplados à proteína G), CCR5 e CXCR4, têm sido identificados como os principais correceptores in vivo para o HIV-1. ${ }^{31}$ Assim, após a ligação da gp120 ao receptor celular CD4, ocorrem alterações conformacionais que facilitam a ligação ao correceptor e subsequente entrada viral. ${ }^{5,25}$ Este evento é decorrente da fusão do envelope viral com a membrana celular, um processo facilitado pela glicoproteína gp41. ${ }^{18}$

A fusão das membranas viral e celular resulta na criação de um poro que conecta o interior do vírion com o citoplasma da célula alvo, facilitando a entrada do capsídeo viral no citoplasma da célula do hospedeiro. ${ }^{32}$ Segue-se então a etapa de desnudamento, que envolve fatores celulares e as proteínas virais MA, Nef e Vif ${ }^{31}$ e consiste na liberação do conteúdo do capsídeo (RNA genômico e as proteínas MA, TR, IN e Vpr) para o citoplasma. ${ }^{25}$

Uma vez no citoplasma, o genoma viral RNA é retrotranscrito para uma fita dupla de DNA pró-viral, pela TR viral. ${ }^{31}$ Após a transcrição reversa, o DNA pró-viral é associado com proteínas virais e celulares em um grande complexo nucleoproteico de pré-integração (PIC) que é transportado para o núcleo celular através do poro nuclear. Além de importantes fatores celulares, três proteínas do HIV associadas ao PIC (MA, Vpr e IN) desenvolvem papel crucial neste transporte. ${ }^{33}$

A dupla fita de DNA linear do PIC é inserida no cromossomo do hospedeiro pela IN viral. ${ }^{31,34}$ Depois da integração, ocorrem as primeiras transcrições do DNA pró-viral pela RNA polimerase II celular, produzindo RNAs virais (genômico e mensageiro) ${ }^{34}$ que são transportados através da membrana do núcleo. No citoplasma, as fitas de RNAm viral são traduzidas produzindo as poliproteínas que darão origem às proteínas virais. ${ }^{31}$

As proteínas Env migram e se inserem na membrana plasmática. As poliproteínas Gag e Gag-Pol também se movem para a membrana celular e começam a montagem do vírion direcionada pela poliproteína Gag. Além disso, enzimas virais, RNA genômico e compostos celulares se associam no nucleocapsídio imaturo. Mais tarde, este complexo brota através da membrana plasmática produzindo um vírion imaturo. ${ }^{31}$

O brotamento dispara a ativação da PR que autocataliticamente cliva as poliproteínas Gag e Gag-Pol, liberando as proteínas estruturais e as enzimas. As proteínas individuais sofrerão futuras interações, de maneira que as proteínas CA e NC formem o nucleocapsídeo cônico e a MA fique associada ao envelope viral. ${ }^{31} \mathrm{O}$ processamento das proteínas virais pela protease leva à formação das partículas virais maduras e infecciosas. ${ }^{34}$

\section{FÁRMACOS USADOS NA TERAPIA ANTIRRETROVIRAL}

Teoricamente todas as etapas do ciclo de replicação viral representam alvos para a terapia antirretroviral. Atualmente, as principais classes de fármacos usadas na terapia antirretroviral (TARV) para combater o HIV incluem inibidores da transcriptase reversa análogos de nucleosídeos (ITRN), inibidores da transcriptase reversa análogos de nucleotídeos (ITRNt), inibidores da transcriptase reversa não análogos de nucleosídeos (ITRNN) e inibidores de protease (IP). Recentemente, foram introduzidos no arsenal terapêutico anti-HIV, inibidores da entrada do vírus na célula, como é o caso do inibidor da fusão vírus-célula (enfuvirtida) e do antagonista de CCR5, (maraviroque), e um inibidor de integrase (raltegravir). ${ }^{9}$

Os ITRN se ligam ao sítio catalítico da TR, enquanto que os ITRNN inibem a TR por interação em um sítio diferente do sítio catalítico produzindo uma inibição alostérica da enzima. ${ }^{18,30}$ Os ITRNN podem ser considerados um grupo de potentes inibidores da TR, tendo uma considerável diversidade estrutural, mas mostrando certas características comuns em sua ação inibitória. ${ }^{18}$

A TARV corrente geralmente inicia com a combinação de três fármacos, sendo dois ITRN associados a um ITRNN ou a um IP. Esta terapia é manejada de acordo com o aparecimento de resistência, toxicidade e comorbidades. ${ }^{9}$

\section{PRODUTOS NATURAIS COM AÇÃO ANTI-HIV}

A pesquisa de produtos naturais com atividade antiviral é focalizada principalmente nas plantas, entre outras razões, pelo fato delas 
poderem ser selecionadas com base em seu uso etnomedicinal. ${ }^{12,35}$ As investigações etnofarmacológicas e etnobotânicas têm sido a principal abordagem reconhecida por cientistas em todo o mundo como uma estratégia de seleção de plantas medicinais. ${ }^{22,36}$ Além disso, as plantas medicinais têm sido utilizadas para o tratamento de uma variedade de enfermidades infecciosas e não infecciosas.$^{37}$ Estima-se que cerca de $25 \%$ dos medicamentos comumente utilizados contêm compostos isolados de plantas e acredita-se que muitas plantas podem ser um rico reservatório para a descoberta de novas substâncias contra doenças infecciosas. ${ }^{38}$

A busca por antivirais vem sendo focalizada em compostos que interfiram em várias partes do ciclo de replicação viral. ${ }^{12}$ Desta forma, muitos extratos vegetais têm sido testados em um screening antiviral primário em cultivos celulares ${ }^{15,39}$ para verificar uma potencial ação antiviral. Este tipo de teste não é especificamente baseado no mecanismo de ação, mas facilita a identificação de produtos naturais que bloqueiem diferentes etapas do ciclo de replicação dos vírus. ${ }^{18}$

Alguns extratos e substâncias isoladas de plantas foram testados em etapas específicas do ciclo de replicação viral tendo, em alguns casos, o mecanismo de ação elucidado. Desta forma, podem ser agrupados de acordo com seus mecanismos inibitórios sobre o HIV. Assim, temos extratos vegetais e compostos isolados que atuam na inibição: da penetração do vírus na célula hospedeira (inibição da ligação do vírus à superfície celular e da penetração viral na membrana celular); da transcrição reversa do RNA viral para DNA pró-viral; da integração do DNA pró-viral ao genoma do hospedeiro; do processamento dos polipeptídeos virais pela protease e, da montagem do genoma e proteínas virais dentro da partícula viral para a maturação final e liberação das partículas infecciosas virais maduras. Existem também aqueles que ainda não possuem o seu mecanismo de ação completamente elucidado, mas que demonstraram ação antiviral pela inibição dos efeitos citopáticos do HIV.

\section{Inibição da entrada do vírus na célula (Inibição da adsorção e fusão viral)}

A entrada do HIV-1 na célula hospedeira é essencial para que o vírus estabeleça uma infecção produtiva e, desta forma, representa um importante alvo para a prevenção da infecção e subsequente transmissão do HIV-1. ${ }^{5}$ Como a entrada do HIV na célula alvo envolve um mecanismo complexo de multietapas, o esforço para identificar agentes farmacológicos que possam interferir neste processo resulta em um grupo de compostos heterogêneos com mecanismos de ação distintos. ${ }^{40}$ Nesta fase inicial da infecção, as etapas geralmente ex- ploradas para a pesquisa de agentes antivirais são a ligação da gp120 do vírus ao receptor CD4 ou aos correceptores celulares (CCR5 e CXCR4) e a penetração viral na membrana celular. ${ }^{19,40}$ A prevenção da fusão do vírus com a membrana da célula hospedeira geralmente se dá pelo bloqueio da glicoproteína transmembrana viral gp41. O bloqueio da fusão celular também bloqueia a transmissão célulacélula do vírus HIV. ${ }^{18}$ Outra forma de inibir a penetração do vírus é a internalização dos receptores celulares CD4, CXCR4 e CCR5, como observado com o diterpeno SJ23B (7) isolado da Euphorbia hyberna. ${ }^{41}$ Várias plantas testadas têm apresentado forte inibição da entrada do HIV na célula (Tabela 1) e algumas possuem substâncias capazes de inibir mais de uma etapa do ciclo viral, como é o caso da geraniina (8) e corilangina (9) que bloqueiam gp120, TR e IN. O extrato de folhas do Phyllanthus amarus apresentou atividade antiHIV in vitro e in vivo, ${ }^{42}$ o que demonstra o real potencial das plantas medicinais para o combate desta infecção.

\section{Inibição da transcriptase reversa}

Uma grande barreira na luta contra a AIDS é a mutação do HIV, que confere resistência contra os inibidores da TR. Por causa da alta taxa de mutação da TR, o surgimento de novas cepas de HIV resistentes é frequente. No plasma de pacientes tem sido detectados mutantes de HIV-1 resistentes a todos os inibidores de TR, incluindo o ITRNN, efavirenz. ${ }^{43}$ Isto tem acelerado as pesquisas de outros inibidores efetivos da TR..$^{18}$ Dentre os produtos derivados de plantas podem-se destacar os inófilos e calanolídeos, que parecem formar uma subclasse de ITRNN que são ativos contra cepas de HIV-1 com mutação na TR, resistentes à maioria dos outros ITRNN. ${ }^{44}$ Desta forma, a síntese de derivados de inófilos e calanolídeos pode levar a compostos com alta potência e seletividade.

Além destas substâncias, várias outras isoladas de plantas têm demonstrado ação inibidora da TR do HIV (Tabela 2), como é o caso dos calanolídeos A (4) e B (10), soulatrolídeo (11), geraniina (8), corilagina (9), inófilo B (12) e P (13), e baicalina (14). Muitas plantas com comprovada ação anti-TR precisam passar por um estudo fitoquímico, com vistas à identificação das substâncias envolvidas nesta ação e para elucidação do mecanismo inibitório (Tabela 2).

\section{Inibição da integrase}

Assim como em outras viroses, o HIV-1 depende de uma integração estável no genoma do hospedeiro, para que ocorra a replicação do RNA viral e a manutenção do estado infectado. ${ }^{18}$ Mutantes de HIV integrase

Tabela 1. Plantas e seus constituintes isolados que apresentam atividade inibitória da entrada do HIV na célula

\begin{tabular}{|c|c|c|c|c|c|c|}
\hline $\begin{array}{l}\text { Planta testada } \\
\text { Família / Espécie }\end{array}$ & Parte utilizada & Substância isolada & Solvente para extração & \% de inibição & Concentração $(\mu \mathrm{g} / \mathrm{mL})$ & Ref. \\
\hline \multicolumn{7}{|l|}{ Cistaceae } \\
\hline Tuberaria lignosa & Toda a planta & Fração rica em elagitaninos & Água & 50 & 2,33 & 60 \\
\hline \multicolumn{7}{|l|}{ Curcubitaceae } \\
\hline Hemsleya jinfushanensis & Tubérculos & Hemslecina A, 22 (Triterpenoide) & Etanol & 50 & 1,76 & 61 \\
\hline Hemsleya jinfushanensis & Tubérculos & Hemslecina B, 23 (Triterpenoide) & Etanol & 50 & 11,95 & 61 \\
\hline \multicolumn{7}{|l|}{ Euphorbiaceae } \\
\hline Euphorbia hyberna & - & SJ23B, 7 (Diterpeno) & - & 50 & $0,076^{*}$ & 41 \\
\hline Phyllanthus amarus ${ }^{a}$ & Folhas & - & Água/etanol & 50 & $2,65 \pm 0,44$ & 42 \\
\hline Phyllanthus amarus ${ }^{a}$ & Folhas & Corilagina, 9 (Galotanino) & Água/etanol & 50 & $0,50 \pm 0,27$ & 42 \\
\hline Phyllanthus amarus ${ }^{a}$ & Folhas & Geraniina, 8 (Elagitanino) & Água/etanol & 50 & $0,48 \pm 0,05$ & 42 \\
\hline \multicolumn{7}{|l|}{ Moraceae } \\
\hline Dorstenia contrajerva $^{a, b}$ & Folhas & Contrajervina,27 (Peptídeo) & - & 50 & $0,20 *$ & 62 \\
\hline \multicolumn{7}{|l|}{ Simaroubaceae } \\
\hline Ailanthus altíssima ${ }^{b}$ & Casca do caule & - & - & 74,9 & 100 & 63 \\
\hline \multicolumn{7}{|l|}{ Theaceae } \\
\hline Camellia sinensis $^{a}$ & Folhas & Galato de epigalocatequina, 29 (Catequina) & Água & 50 & $4,5^{*}$ & 59 \\
\hline
\end{tabular}

${ }^{\mathrm{a}}$ Inibem a ligação CD4-gp120, in vitro; ${ }^{b}$ inibem a fusão vírus-célula; * concentração em $\mu \mathrm{M}$ 


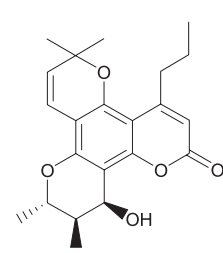

(10) Calanolídeo B

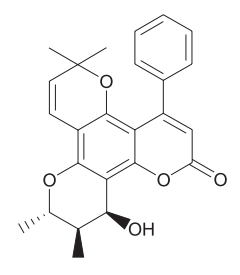

(11) Soulatrolídeo

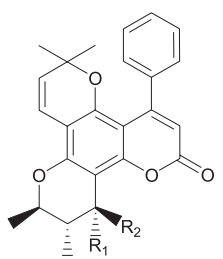

(12) Inófilo $B: \mathrm{R}_{1}=\mathrm{H}, \mathrm{R}_{2}=\mathrm{OH}$ (13) Inófilo $P$ : $\mathrm{R}_{1}=\mathrm{OH}, \mathrm{R}_{2}=\mathrm{H}$<smiles>O=C(O)C1(O)OC(Oc2cc3oc(-c4ccccc4)cc(=O)c3c(O)c2O)C(O)C(O)C1O</smiles>

(14) Baicalina

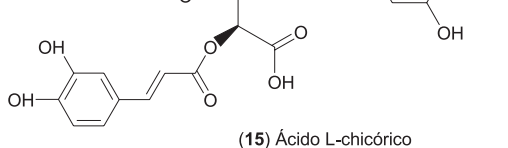<smiles>COC1=CC(=O)c2ccc3cc(OC)cc(O)c3c2C1=O</smiles>
(16) Denbinobina<smiles>Oc1cc(O)c2c(c1)O[C@H](c1ccc(O)c(O)c1)[C@H](O)C2</smiles>

(17) Catequina<smiles>O=c1c(O)c(-c2ccc(O)c(O)c2)oc2cc(O)cc(O)c12</smiles>

(18) Quercetina

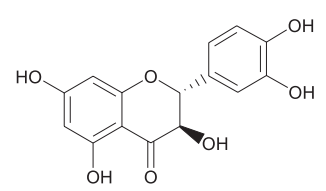

(19) Taxifolina negativos não produzem partículas virais infecciosas, ${ }^{12} \mathrm{o}$ que demonstra que a inibição da IN contribui para a inibição da replicação viral.

As pesquisas de inibidores da integrase não são tão abundantes quando comparadas com as dos inibidores da TR e PR, mas existem alguns pontos que podem estimular a busca de substâncias ativas contra este alvo. A IN é altamente conservada, o que diminui o aparecimento de resistência viral, e não existe um homólogo celular desta enzima, o que pode diminuir o aparecimento de efeitos adversos. ${ }^{12,45}$

Compostos de origem natural podem ser muito úteis como protótipos para novos inibidores. ${ }^{45}$ Reinke e colaboradores ${ }^{46}$ demonstraram que o ácido $L$-chicórico (L-CA) (15) é um inibidor não competitivo reversível da IN, in vitro, e da integração do HIV in vivo. Esta substância é encontrada em plantas como a Echinacea purpurea ${ }^{47}$ Além desta, outras plantas são fontes de substâncias inibidoras da IN, algumas das quais agem em concentrações micromolares $^{48,49}$ (Tabela 3).

\section{Inibição da protease}

A PR do HIV desempenha um papel crítico na produção de partículas virais funcionalmente infecciosas sendo, assim, um alvo terapêutico apropriado para as pesquisas de inibidores do HIV. Neste aspecto, inibidores da PR do HIV são efetivos inibidores da replicação viral e podem ser aplicados nos estágios finais do ciclo de replicação do HIV. ${ }^{18}$ Muitas plantas foram testadas quanto à atividade inibitória da PR do HIV, como se pode observar na Tabela 4, mas os detalhes do mecanismo de inibição desta enzima, pelos diferentes extratos e substâncias isoladas, ainda requerem estudos para a completa elucidação.
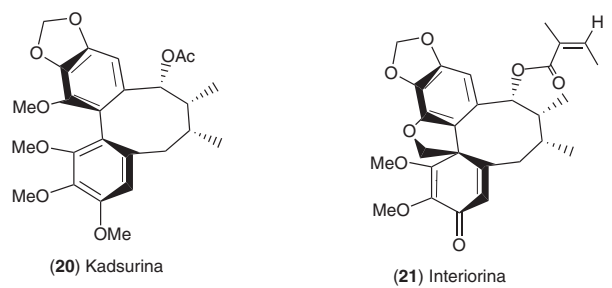

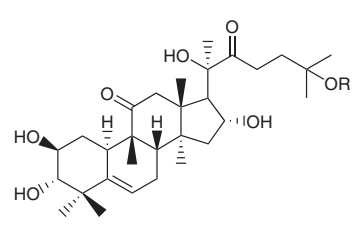

(22) Hemslecina $A: R=A c$
(23) Hemslecina $B: R=H$

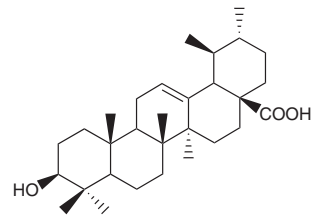

(24) Ác. ursólico

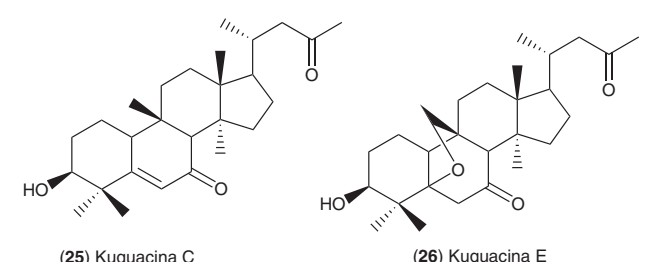

ERDDHRCGPDYGNPSCSGDRCCSIYNWCGGGSSYCSGGSCRYQCWY (27) Contrajervina

RNGDPTFCGETCRVIPVCTYSAALGCTCDDRSDGLCK

(28) Palicoureina

\section{Outras atividades anti-HIV de produtos naturais}

Várias plantas foram identificadas como possuidoras de potente atividade anti-HIV baseada em testes celulares, mas algumas não possuem o mecanismo de ação estabelecido ${ }^{50-52}$ (Tabela 5). Em geral, a avaliação da inibição da replicação do HIV se dá pela pesquisa de efeitos citopáticos, quantificação da p24 e da TR. Bedoya e colaboradores ${ }^{53}$ demonstraram a atividade anti-HIV, in vitro, dos extratos aquosos de Tuberaria lignosa e Sanguisorba minor magnolii utilizando ensaio colorimétrico com sal de tetrazolium [brometo de 3-(4,5-dimetiltiazol-2-il)-2,5-difeniltetrazólio (MTT)]. Estes extratos mostraram efeito inibitório contra a indução de infecção de células MT-2 pelo HIV-1 em concentrações variando de 12,5 a 50 e $50 \mu \mathrm{g} /$ $\mathrm{mL}$, respectivamente.

Além da ação típica sobre as principais enzimas do HIV, muitos produtos naturais possuem ação em outras etapas do ciclo viral. Porém, independente do mecanismo de ação pode-se observar como resultado final a inibição da replicação viral (Tabela 5).

A partir do ácido betulínico isolado de folhas de Syzigium claviflorum $^{8,54}$ foram preparados derivados como o ácido 3-O-(3',3'dimetilsuccinil) betulinico, conhecido como bevirimato (3), que inibe a maturação do HIV.${ }^{54} \mathrm{O}$ bevirimato (3) atua na etapa final do processamento da poliproteína Gag, impedindo a liberação da proteína do capsídio (CA/p24). Isto resulta na liberação de partículas virais não infecciosas, bloqueando a disseminação da infecção para novas células. ${ }^{17,54} \mathrm{O}$ bevirimato $(\mathbf{3})$ possui potentente atividade in vitro, com $\mathrm{IC}_{90}$ de 22,1 ng/mL $(37,8 \mathrm{nM}),{ }^{55}$ e em estudos de Fase II mostrou significativa redução da carga viral e boa tolerabilidade, sem evidências de desenvolvimento rápido de resistência. ${ }^{56}$

A atividade antiviral de antraquinonas e compostos relacionados também foi recentemente relatada. A 1,4-fenantrenoquinona (denbinobina) (16), foi isolada de uma variedade de Cannabis sativa. $A$ denbinobina (16) não afeta a transcrição reversa e a integração, 
Tabela 2. Plantas e seus constituintes isolados que apresentam atividade inibitória da TR do HIV in vitro

\begin{tabular}{|c|c|c|c|c|c|c|}
\hline $\begin{array}{l}\text { Planta testada } \\
\text { Família / Espécie }\end{array}$ & Parte utilizada & Substância isolada & Solvente para extração & $\%$ de inibição ${ }^{a}$ & Concentração $(\mu \mathrm{g} / \mathrm{mL})$ & Ref \\
\hline $\begin{array}{l}\text { Anacardiaceae } \\
\text { Rhus chinensis }\end{array}$ & Caule & - & Butanol & 11,4 & 100 & 64 \\
\hline $\begin{array}{l}\text { Acanthaceae } \\
\text { Acanthus ebracteatus } \\
\text { Andrographis paniculata } \\
\text { Justicia gendarussa } \\
\text { Justicia valida }\end{array}$ & $\begin{array}{l}\text { Parte aérea } \\
\text { Toda a planta } \\
\text { Parte aérea } \\
\text { Parte aérea }\end{array}$ & $x^{2}$ & $\begin{array}{l}\text { Água } \\
\text { Água } \\
\text { Água } \\
\text { Água }\end{array}$ & $\begin{array}{l}57,21 \\
87,67 \\
90,75 \\
68,64\end{array}$ & $\begin{array}{l}200 \\
200 \\
200 \\
200\end{array}$ & $\begin{array}{l}65 \\
65 \\
65 \\
65\end{array}$ \\
\hline $\begin{array}{l}\text { Annonaceae } \\
\text { Xylopia frutescens }\end{array}$ & Casca e folhas & - & Metanol & 50 & 22 & 50 \\
\hline $\begin{array}{l}\text { Asphodelaceae } \\
\text { Bulbine alooides (L.) Willd. } \\
\text { Bulbine alooides (L.) Willd. }\end{array}$ & $\begin{array}{l}\text { Raiz } \\
\text { Raiz }\end{array}$ & 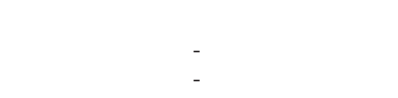 & $\begin{array}{c}\text { Água } \\
\text { Etanol 95\% }\end{array}$ & $\begin{array}{l} \pm 50 \\
\pm 50\end{array}$ & $\begin{array}{l}200 \\
200\end{array}$ & $\begin{array}{l}66 \\
66\end{array}$ \\
\hline $\begin{array}{l}\text { Boraginaceae } \\
\text { Cordia spinescens } \\
\text { Lobostemon trigonus }\end{array}$ & $\begin{array}{l}\text { Folhas } \\
\text { Folhas }\end{array}$ & - & $\begin{array}{l}\text { Água } \\
\text { Água }\end{array}$ & $\begin{array}{l}50 \\
50\end{array}$ & $\begin{array}{c}6 \\
49\end{array}$ & $\begin{array}{l}50 \\
67\end{array}$ \\
\hline $\begin{array}{l}\text { Cannaceae } \\
\text { Canna indica } \mathrm{L} \text {. } \\
\text { Canna indica } \mathrm{L} \text {. } \\
\text { Canna indica } \mathrm{L} \text {. }\end{array}$ & $\begin{array}{l}\text { Rizoma } \\
\text { Rizoma } \\
\text { Rizoma }\end{array}$ & $\begin{array}{l}- \\
\text { Proteína Cip31 } \\
\text { Proteína Cip14 }\end{array}$ & $\begin{array}{l}\text { Água } \\
\text { Água } \\
\text { Água }\end{array}$ & $\begin{array}{c}92,97 \\
50 \\
50\end{array}$ & $\begin{array}{c}200 \\
17,41 \\
19,25\end{array}$ & $\begin{array}{l}65 \\
65 \\
65\end{array}$ \\
\hline $\begin{array}{l}\text { Capparaceae } \\
\text { Capparis spinosa }\end{array}$ & Semente & Proteína & Água & 50 & $0,23 *$ & 68 \\
\hline $\begin{array}{l}\text { Celastraceae } \\
\text { Elaeodendron transvaalensis } \\
\text { Elaeodendron transvaalensis }\end{array}$ & $\begin{array}{l}\text { Raiz } \\
\text { Raiz }\end{array}$ & 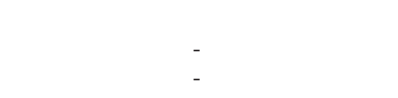 & $\begin{array}{l}\text { Água } \\
\text { Metanol }\end{array}$ & $\begin{array}{l}50 \\
50\end{array}$ & $\begin{array}{c}80 \\
131\end{array}$ & $\begin{array}{l}48 \\
48\end{array}$ \\
\hline $\begin{array}{l}\text { Clusiaceae } \\
\text { Calophyllum brasiliense } \\
\text { Calophyllum brasiliense } \\
\text { Calophyllum brasiliense } \\
\text { Calophyllum inophyllum } \\
\text { Calophyllum inophyllum }\end{array}$ & $\begin{array}{l}\text { Folhas } \\
\text { Folhas } \\
\text { Folhas } \\
\text { Folhas e galhos } \\
\text { Folhas e galhos }\end{array}$ & $\begin{array}{c}\text { Calanolídeo A, } 4 \text { (Dipiranocumarina) } \\
\text { Calanolídeo B, } 10 \text { (Dipiranocumarina) } \\
\text { Soulatrolídeo, } 11 \text { (Dipiranocumarina) } \\
\text { Inófilo B, } 12 \text { (Dipiranocumarina) } \\
\text { Inófilo P, } 13 \text { (Dipiranocumarina) }\end{array}$ & $\begin{array}{l}- \\
- \\
- \\
- \\
-\end{array}$ & $\begin{array}{l}81,5 \pm 0.9 \\
76,2 \pm 2,2 \\
77,7 \pm 1,6 \\
50 \\
50\end{array}$ & $\begin{array}{l}1.000^{*} \\
1.00 *^{*} \\
1.000^{*} \\
0,038^{*} \\
0,130^{*}\end{array}$ & $\begin{array}{l}69 \\
69 \\
69 \\
44 \\
44\end{array}$ \\
\hline $\begin{array}{l}\text { Combretaceae } \\
\text { Combretum hartmannianum } \\
\text { Combretum molle } \\
\text { Combretum molle } \\
\text { Terminalia sericea }\end{array}$ & $\begin{array}{l}\text { Folhas } \\
\text { Raiz } \\
\text { Raiz } \\
\text { Raiz }\end{array}$ & $\begin{array}{l}- \\
- \\
-\end{array}$ & $\begin{array}{l}\text { Metanol } \\
\text { Água } \\
\text { Metanol }\end{array}$ & $\begin{array}{c}99,7 \\
50 \\
50 \\
50\end{array}$ & $\begin{array}{c}66 \\
37,5 \\
9,5 \\
43\end{array}$ & $\begin{array}{l}70 \\
48 \\
48 \\
71\end{array}$ \\
\hline $\begin{array}{l}\text { Compositae } \\
\text { Baccharis trinervis } \\
\text { Calea jamaicensis } \\
\text { Gynura pseudochina }\end{array}$ & $\begin{array}{l}\text { Partes aéreas } \\
\text { Ramos } \\
\text { Folhas }\end{array}$ & 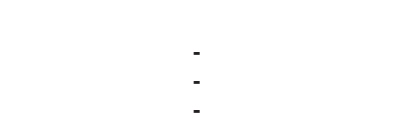 & $\begin{array}{l}\text { Água } \\
\text { Água } \\
\text { Água }\end{array}$ & $\begin{array}{c}50 \\
50 \\
58,05\end{array}$ & $\begin{array}{c}50 \\
15 \\
200\end{array}$ & $\begin{array}{l}50 \\
50 \\
65\end{array}$ \\
\hline $\begin{array}{l}\text { Convolvulaceae } \\
\text { Argyreia nervosa } \\
\text { Ipomoea aquatica } \\
\text { Ipomoea cairica } \\
\text { Ipomoea cárnea }\end{array}$ & $\begin{array}{l}\text { Parte aérea } \\
\text { Toda a planta } \\
\text { Toda a planta } \\
\text { Parte aérea }\end{array}$ & 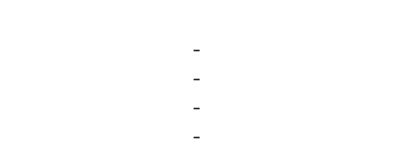 & $\begin{array}{l}\text { Água } \\
\text { Água } \\
\text { Água } \\
\text { Água }\end{array}$ & $\begin{array}{l}84,00 \\
55,49 \\
51,58 \\
98,95\end{array}$ & $\begin{array}{l}200 \\
200 \\
200 \\
200\end{array}$ & $\begin{array}{l}65 \\
65 \\
65 \\
65\end{array}$ \\
\hline $\begin{array}{l}\text { Cornaceae } \\
\text { Cornus kousa }\end{array}$ & Caule e folhas & - & Metanol & 50 & 6,3 & 71 \\
\hline $\begin{array}{l}\text { Euphorbiaceae } \\
\text { Alchornea cordifolia } \\
\text { Bridelia micrantha Baill } \\
\text { Bridelia micrantha Baill } \\
\text { Chamaesyce hyssopifolia } \\
\text { Jatropha curcas L. } \\
\text { Mallotus japonicus } \\
\text { Phyllanthus amarus } \\
\text { Phyllanthus amarus } \\
\text { Phyllanthus amarus } \\
\text { Ricinus communis L. }\end{array}$ & $\begin{array}{c}\text { Fruto } \\
\text { Raiz } \\
\text { Raiz } \\
\text { Toda a planta } \\
\text { Folhas } \\
\text { Caule } \\
\text { Folhas } \\
\text { Folhas } \\
\text { Folhas } \\
\text { Folhas }\end{array}$ & $\begin{array}{c}- \\
- \\
- \\
- \\
- \\
- \\
- \\
\text { Corilagina, } 9 \text { (Galotanino) } \\
\text { Geraniina, } 8 \text { (Elagitanino) } \\
-\end{array}$ & $\begin{array}{c}\text { Água } \\
\text { Água } \\
\text { Metanol } \\
\text { Água e metanol } \\
\text { Metanol } \\
\text { Água } \\
\text { Água/etanol } \\
\text { Água/etanol } \\
\text { Água/etanol } \\
\text { Água }\end{array}$ & $\begin{array}{l}90 \\
50 \\
50 \\
50 \\
50 \\
50 \\
50 \\
50 \\
50 \\
50\end{array}$ & $\begin{array}{c}0,04 \\
18,5 \\
10,5 \\
8 \\
50 \\
11,9 \\
8,17 \pm 1,73 \\
6,24 \pm 2,11 \\
2,53 \pm 1,40 \\
42,5\end{array}$ & $\begin{array}{l}39 \\
48 \\
48 \\
50 \\
50 \\
71 \\
42 \\
42 \\
42 \\
48\end{array}$ \\
\hline $\begin{array}{l}\text { Fabaceae } \\
\text { Glycine max } \\
\text { Mucuna coriacea } \text { Baker } \\
\text { Peltophorum africanum } \\
\text { Peltophorum africanum } \\
\text { Peltophorum africanum } \\
\text { Peltophorum africanum }\end{array}$ & $\begin{array}{c}\text { Sementes } \\
\text { Raiz } \\
\text { Raiz } \\
\text { Raiz } \\
\text { Casca do caule } \\
\text { Raiz e casca do caule }\end{array}$ & $\begin{array}{c}\text { Proteína } \\
- \\
- \\
- \\
- \\
\text { Galotanino }\end{array}$ & $\begin{array}{l}\text { Água } \\
\text { Metanol } \\
\text { Água } \\
\text { Metanol } \\
\text { Metanol } \\
\text { Metanol }\end{array}$ & $\begin{array}{l}50 \\
50 \\
50 \\
50 \\
50 \\
50\end{array}$ & $\begin{array}{c}0,71 \\
10,5 \\
38,3 \\
8 \\
3,5 \\
6^{*}\end{array}$ & $\begin{array}{l}73 \\
48 \\
48 \\
48 \\
48 \\
48\end{array}$ \\
\hline $\begin{array}{l}\text { Flacourtiaceae } \\
\text { Lindackeria laurina }\end{array}$ & Folhas & - & Metanol & 50 & 19 & 50 \\
\hline $\begin{array}{l}\text { Hypoxidaceae } \\
\text { Hypoxis sobolifera } \\
\text { Hypoxis sobolifera }\end{array}$ & $\begin{array}{l}\text { Semente } \\
\text { Semente }\end{array}$ & $\begin{array}{l}- \\
-\end{array}$ & $\begin{array}{c}\text { Água } \\
\text { Etanol 95\% }\end{array}$ & $\begin{array}{l} \pm 84 \\
\pm 55\end{array}$ & $\begin{array}{l}200 \\
200\end{array}$ & $\begin{array}{l}66 \\
66\end{array}$ \\
\hline
\end{tabular}


Tabela 2. Continuação

\begin{tabular}{|c|c|c|c|c|c|c|}
\hline $\begin{array}{l}\text { Planta testada } \\
\text { Família / Espécie }\end{array}$ & Parte utilizada & Substância isolada & Solvente para extração & $\%$ de inibição ${ }^{a}$ & Concentração $(\mu \mathrm{g} / \mathrm{mL})$ & Ref. \\
\hline \multicolumn{7}{|l|}{ Labiatae } \\
\hline Hyptis lantanifolia & Partes aéreas & - & Água & 50 & 7 & 50 \\
\hline Vitex glabrata & Ramos & - & Água & 98,64 & 200 & 65 \\
\hline Vitex negundo & Partes aéreas & - & Água & 96,70 & 200 & 65 \\
\hline Vitex rotundifolia & Partes aéreas & - & Água & 55,44 & 200 & 65 \\
\hline Vitex trifólia & Partes aéreas & - & Água & 98,06 & 200 & 65 \\
\hline \multicolumn{7}{|l|}{ Lamiaceae } \\
\hline Leonotis leonurus (L.) R.Br. & Folhas & - & Água & \pm 60 & 200 & 66 \\
\hline Ocimum gratissimum & Folhas & - & Água & 90 & 0,114 & 39 \\
\hline Scutellariae radix & - & Baicalina, 14 (Flavonoide) & - & 50 & 2 & 74 \\
\hline \multicolumn{7}{|l|}{ Malpighiaceae } \\
\hline Tetrapteris macrocarpa & Partes aéreas & - & Metanol & 50 & 8 & 50 \\
\hline \multicolumn{7}{|l|}{ Malvaceae } \\
\hline Pavonia schiedeana & Partes aéreas & - & Metanol & 50 & 16 & 50 \\
\hline \multicolumn{7}{|l|}{ Moraceae } \\
\hline Ficus polita & Folhas & - & Água & 90 & 0,1 & 39 \\
\hline \multicolumn{7}{|l|}{ Plumbaginaceae } \\
\hline Limonium tetragonum & Raiz & - & Metanol & 50 & 7,5 & 71 \\
\hline \multicolumn{7}{|l|}{ Rosaceae } \\
\hline Agrimonia pilosa & Toda a planta & - & Metanol & 50 & 8,9 & 71 \\
\hline \multicolumn{7}{|l|}{ Rhamnaceae } \\
\hline Ziziphus mucronata Willd & Folhas & - & Água & 50 & 77,5 & 48 \\
\hline Ziziphus mucronata Willd & Folhas & - & Metanol & 50 & 81,5 & 48 \\
\hline \multicolumn{7}{|l|}{ Rutaceae } \\
\hline Clausena excavata & Partes aéreas & - & Água & 89,15 & 200 & 65 \\
\hline Murraya koenigii & Partes aéreas & - & Água & 82,47 & 200 & 65 \\
\hline \multicolumn{7}{|l|}{ Verbenaceae } \\
\hline Aegiphila anômala & Folhas & - & Água & 50 & 24 & 50 \\
\hline Stachytarpheta jamaicensis & Toda a planta & - & Água & 69,28 & 200 & 65 \\
\hline
\end{tabular}

*Concentração em $\mu \mathrm{M}$

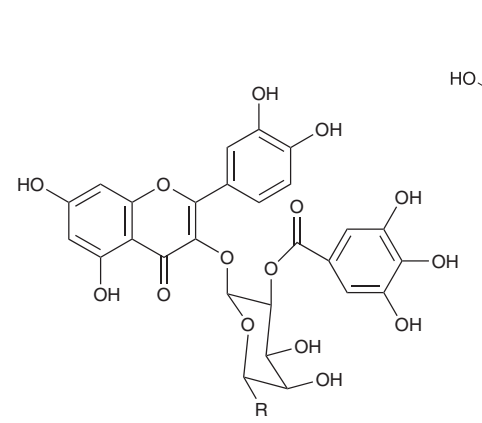

(30) Quercetina 3-O-(2"-galoil)- $\alpha$-L-arabinopiranosideo: $\mathrm{R}=\mathrm{H}$

(31) Quercetina 3-O-(2",6"-O-digaloil)- $\beta$-D-galactopiranosideo:

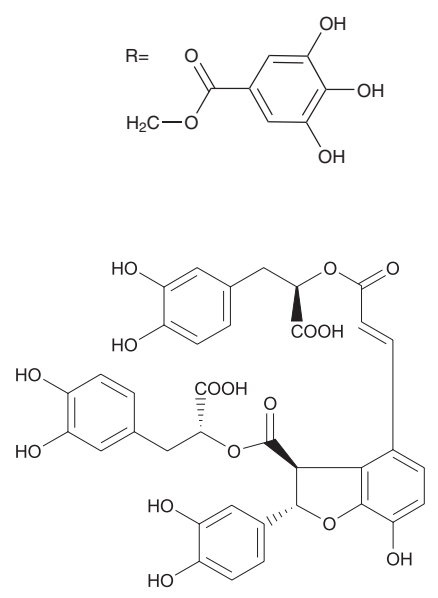

(33) Ác. litospermico B

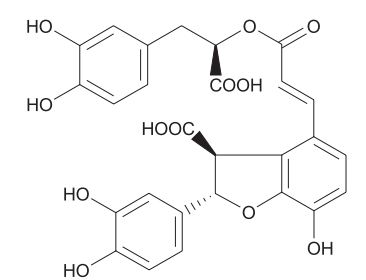

(32) Ác. litospermico

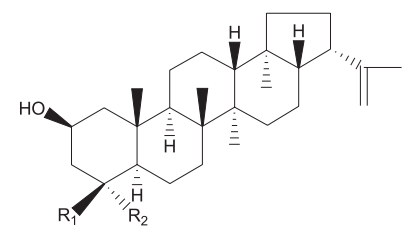

(34) Ác. drioptérico $A: R_{1}=\mathrm{COOH}, \mathrm{R}_{2}=\mathrm{CH}_{3}$ (35) Ác. drioptérico $B$ : $\mathrm{R}_{1}=\mathrm{CH}_{3}, \mathrm{R}_{2}=\mathrm{COOH}$

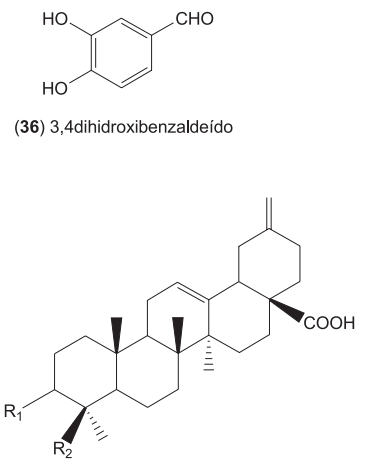

(38) ác. 16 $\beta$-hidroxi -30-noroleana-12,20(29)-dien-28-oico $\mathrm{R}_{1}=\beta-\mathrm{OH} \quad \mathrm{R}_{2}=\mathrm{CH}_{3}$
(39) ác. 3 $\alpha$,24-didroxi-30-noroleana-12,20(29)-dien-28-oico $\mathrm{R}_{1}=\alpha-\mathrm{OH} \quad \mathrm{R}_{2}=\mathrm{CH}_{2} \mathrm{OH}$

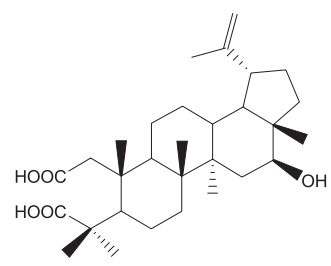

(37) ác.16 $\beta$-hidroxi-2,3-seco-lup-20(29)-ene-2,3-dioico
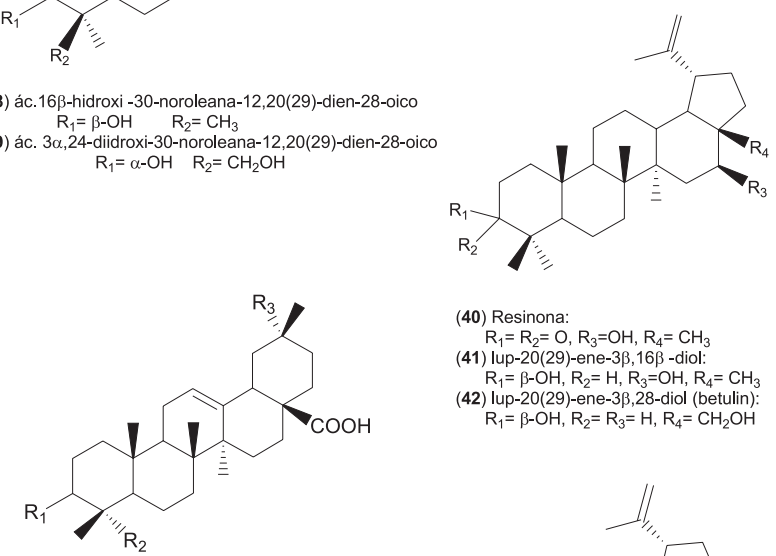

(43) Ác. 3-O-acetiloleanolico:

$\mathrm{R}_{1}=\mathrm{CH}_{3} \mathrm{COO}, \mathrm{R}_{2}=\mathrm{CH}_{3}, \mathrm{R}_{3}=\mathrm{CH}_{3}$

44) Ác. mesenbriantemoidgenico:

$\mathrm{R}_{1}=\beta-\mathrm{OH}, \mathrm{R}_{2}=\mathrm{CH}_{3}, \mathrm{R}_{3}=\mathrm{CH}_{2} \mathrm{OH}$

(45) Ác. 3ß,23-diddroxi-olean-12-en-28-oico: $\mathrm{R} 1=\beta-\mathrm{OH}, \mathrm{R}_{2}=\mathrm{CH}_{2} \mathrm{OH}, \mathrm{R}_{3}=\mathrm{CH}_{3}$

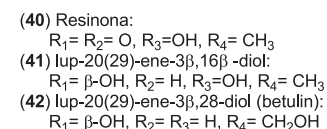

$\mathrm{R}_{1}=\beta-\mathrm{OH}, \mathrm{R}_{2}=\mathrm{R}_{3}=\mathrm{H}, \mathrm{R}_{4}=\mathrm{CH}_{2} \mathrm{OH}$
(4) lop

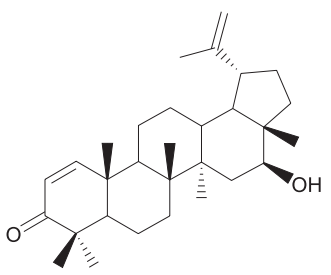

(46) 16 3-hidroxilupano-1,20(29)-dien-3-ona 
Tabela 3. Plantas e seus constituintes que apresentam atividade inibitória da IN do HIV in vitro

\begin{tabular}{|c|c|c|c|c|c|c|}
\hline $\begin{array}{l}\text { Planta testada } \\
\text { Família / Espécie }\end{array}$ & Parte utilizada & Substância isolada & Solvente & $\%$ de inibição & Concentração $(\mu \mathrm{g} / \mathrm{ml})$ & Ref. \\
\hline \multicolumn{7}{|l|}{ Aceraceae } \\
\hline Acer okamotoanum Nakai & Folhas & $\begin{array}{c}\text { Quercetina-3-O-(2"-galoil)- } \alpha \text {-L-arabinopiranosideo, } 30 \\
\text { (Flavonoide glicosilado) }\end{array}$ & Acetato de etila & 50 & $18,1 \pm 1,3$ & 75 \\
\hline Acer okamotoanum Nakai & Folhas & $\begin{array}{l}\text { Quercetina-3-O-(2",6"-O-digaloil)- } \beta \text {-D-galactopiranosideo, } \\
\text { 31 (Flavonoide glicosilado) }\end{array}$ & Acetato de etila & 50 & $24,2 \pm 6,6$ & 75 \\
\hline \multicolumn{7}{|l|}{ Dioscoreaceae } \\
\hline Dioscorea birmanica & Rizoma & - & Água & 50 & $4,5 \pm 0,8$ & 76 \\
\hline Dioscorea birmanica & Rizoma & - & Etanol & 50 & $4,7 \pm 0,4$ & 76 \\
\hline \multicolumn{7}{|l|}{ Euphorbiaceae } \\
\hline Phyllanthus amarus & Folhas & - & Água/etanol & 50 & $0,48 \pm 0,11$ & 42 \\
\hline Phyllanthus amarus & Folhas & Corilagina, 9 (Galotanino) & Água/etanol & 50 & $0,21 \pm 0,05$ & 42 \\
\hline Phyllanthus amarus & Folhas & Geraniina, 8 (Elagitanino) & Água/etanol & 50 & $0,16 \pm 0,07$ & 42 \\
\hline \multicolumn{7}{|l|}{ Fabaceae } \\
\hline Peltophorum africanum & Raiz e casca do caule & Galotanino & Metanol & 100 & $100 *$ & 48 \\
\hline Peltophorum africanum & Raiz e casca do caule & Catequina, 17 (Flavonoide) & Metanol & 65 & $100 *$ & 48 \\
\hline \multicolumn{7}{|l|}{ Lamiaceae } \\
\hline Salvia miltiorrhiza & Rizoma & Ác. litospermico, 32 (derivado do ac. cafeico) & - & 50 & $0,83^{*}$ & 49 \\
\hline Salvia miltiorrhiza & Rizoma & Ác. litospermico B, $\mathbf{3 3}$ (derivado do ac. cafeico) & - & 50 & $0,48^{*}$ & 49 \\
\hline \multicolumn{7}{|l|}{ Smilacaceae } \\
\hline Smilax corbularia & Rizoma & - & Água & 50 & $5,4 \pm 0,5$ & 76 \\
\hline Smilax corbularia & Rizoma & - & Etanol & 50 & $1,9 \pm 0,2$ & 76 \\
\hline Smilax glabra & Rizoma & - & Água & 50 & $8,5 \pm 0,8$ & 76 \\
\hline Smilax glabra & Rizoma & - & Etanol & 50 & $6,7 \pm 0,4$ & 76 \\
\hline
\end{tabular}

*Concentração em $\mu \mathrm{M}$<smiles>COc1ccc([C@H](O)C(C)Oc2ccc([C@H]3O[C@@H](c4ccc(OC(C)[C@@H](O)c5ccc(OC)c(OC)c5)c(OC)c4)[C@H](C)[C@@H]3C)cc2OC)cc1OC</smiles>

(47) Manassantina A<smiles></smiles>

(48) Saururina B<smiles>[R]c1c([R])c2c(c([R])c1O)C(=O)C[C@H](c1ccccc1)O2</smiles>

(51) Lavinal: $\mathrm{R}=\mathrm{OH}, \mathrm{R}_{1}=\mathrm{CHO}, \mathrm{R}_{2}=\mathrm{Me}$ 52) Desmetoxiateucinol: $\mathrm{R}=\mathrm{OH}, \mathrm{R}_{1}=\mathrm{Me}, \mathrm{R}_{2}=\mathrm{M}$ (53) Desmosflavanona II: $\mathrm{R}=\mathrm{OMe}, \mathrm{R}_{1}=\mathrm{Me}, \mathrm{R}_{2}=\mathrm{CHO}$<smiles>COc1c(C)c(O)c(C(=O)/C=C/c2ccccc2)c(O)c1C=O</smiles>

(54) 2-Metoxi-3-metil-4,6-diidroxi-5-(3- hidroxi) cinamoilbenzaldeido

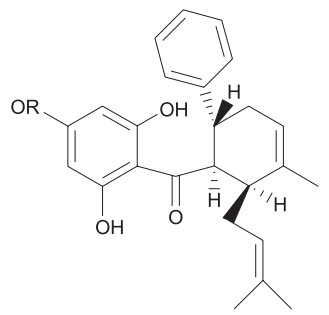
(49) Panduratina $A: R=M e$
(50) Hidroxipanduratin $A: R=H$

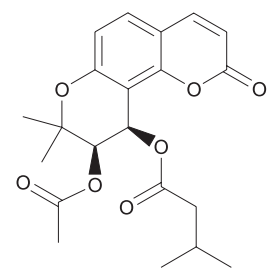

(55) Suksdorfina<smiles>COc1cn2c3ccccc3c3ccnc(c1=O)c32</smiles>

(56) Drimaritina

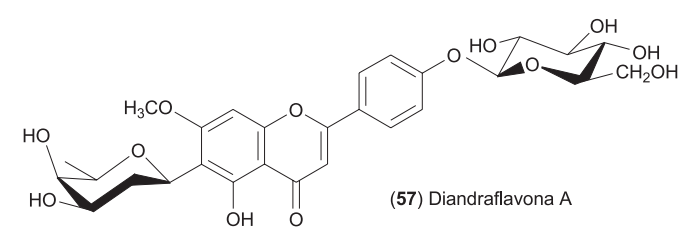

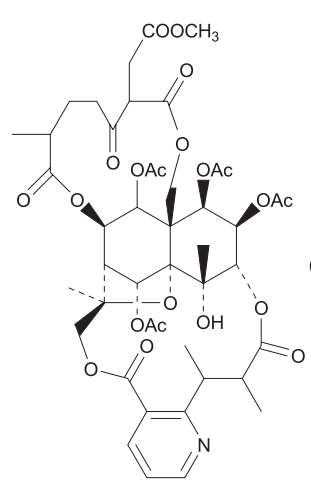

(58) Triptonina A

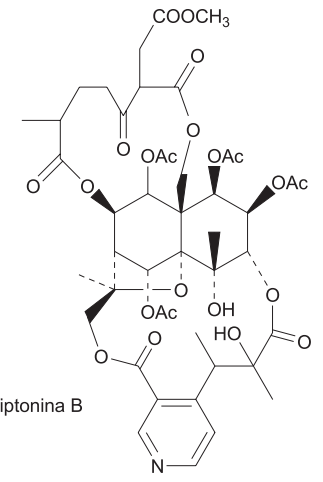

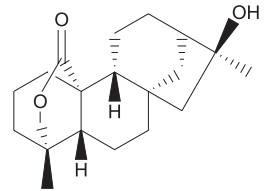

(60) Neotripterifordina<smiles>CCCc1cc(=O)oc2c3c(c4c(c12)OC(C)(C)C=C4)O[C@H](C)[C@H](C)[C@H]3O</smiles>

(62) Calanolídeo F

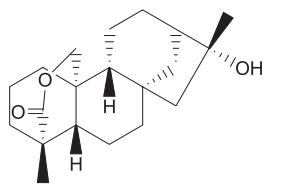

(61) Tripterifordina 
Tabela 4. Plantas e seus constituintes que apresentam atividade inibitória da PR do HIV, in vitro

\begin{tabular}{|c|c|c|c|c|c|c|}
\hline $\begin{array}{l}\text { Planta testada } \\
\text { Família / Espécie }\end{array}$ & Parte utilizada & Substância isolada & Solvente & \% de inibição & $\begin{array}{l}\text { Concentração } \\
(\mu \mathrm{g} / \mathrm{mL})\end{array}$ & Ref. \\
\hline Annonaceae & & & & & & \\
\hline Xylopia frutescens & Casca & - & Metanol & 50 & 46 & 50 \\
\hline $\begin{array}{l}\text { Araliaceae } \\
\text { Radix notoginseng }\end{array}$ & Raiz & - & Metanol & $78,3 \pm 7$ & 200 & 14 \\
\hline \multicolumn{7}{|l|}{ Aspiadaceae } \\
\hline Dryopteris crassirhizoma & Rizoma & Ácido ursólico, 24 (Triterpeno) & Acetato de etila & 50 & $8,9^{*}$ & 77 \\
\hline Dryopteris crassirhizoma & Rizoma & Ác. driopterico A, 34 (Triterpeno) & Acetato de etila & 50 & $26,5^{*}$ & 77 \\
\hline Dryopteris crassirhizoma & Rizoma & Ác. driopterico B, 35 (Triterpeno) & Acetato de etila & 50 & $44,5^{*}$ & 77 \\
\hline Dryopteris crassirhizoma & Rizoma & 3,4 di-hidroxibenzaldeído, 36 & Clorofórmio & 50 & $27,5^{*}$ & 77 \\
\hline \multicolumn{7}{|l|}{ Asteraceae } \\
\hline Senecio scandens & Toda a planta & - & Água & $83,2 \pm 3,5$ & 200 & 14 \\
\hline Senecio scandens & Toda a planta & - & Metanol & $81,6 \pm 3,4$ & 200 & 14 \\
\hline Chrysanthemum moriforlium & Capítulo & - & Água & $84,6 \pm 2,4$ & 200 & 14 \\
\hline Chrysanthemum moriforlium & Capítulo & - & Metanol & $60,6 \pm 4,1$ & 200 & 14 \\
\hline $\begin{array}{l}\text { Blechnaceae } \\
\text { Woodwardia unigemmata }\end{array}$ & Rizoma & - & Metanol & $91,9 \pm 6,5$ & 200 & 14 \\
\hline \multicolumn{7}{|l|}{ Boraginaceae } \\
\hline Cordia spinescens & Folhas & - & Água & 50 & 100 & 50 \\
\hline Lithospermum erythrorhizon & Semente & - & Metanol & $57,6 \pm 1,9$ & 200 & 14 \\
\hline \multicolumn{7}{|l|}{ Dioscoreaceae } \\
\hline Dioscorea birmanica & Rizoma & - & Água & 50 & $95,0 \pm 2,5$ & 76 \\
\hline Dioscorea membranácea & Rizoma & - & Metanol & 50 & $48,0 \pm 1,6$ & 76 \\
\hline $\begin{array}{l}\text { Erythroxylaceae } \\
\text { Erythroxylum citrifolium }\end{array}$ & Tronco & - & Água & 50 & 43 & 50 \\
\hline \multicolumn{7}{|l|}{ Euphorbiaceae } \\
\hline $\begin{array}{l}\text { Phyllanthus amarus } \\
\text { Phyllanthus amarus }\end{array}$ & $\begin{array}{l}\text { Folhas } \\
\text { Folhas }\end{array}$ & Geraniina, 8 (Elagitanino) & $\begin{array}{l}\text { Agua/ etanol } \\
\text { Água/ etanol }\end{array}$ & $\begin{array}{l}50 \\
50\end{array}$ & $\begin{array}{c}21,80 \pm 3,66 \\
6,28 \pm 2,51\end{array}$ & $\begin{array}{l}42 \\
42\end{array}$ \\
\hline \multicolumn{6}{|l|}{ Fabaceae } & 14 \\
\hline $\begin{array}{l}\text { Flacourtiaceae } \\
\text { Lindackeria laurina }\end{array}$ & Folhas & - & Água & 50 & 54 & 50 \\
\hline $\begin{array}{l}\text { Lamiaceae } \\
\text { Prunella vulgaris } \\
\text { Scutellaria baicalensis } \\
\text { Scutellaria baicalensis }\end{array}$ & $\begin{array}{c}\text { Toda a planta } \\
\text { Raiz } \\
\text { Raiz }\end{array}$ & $\begin{array}{l}- \\
- \\
-\end{array}$ & $\begin{array}{l}\text { Água } \\
\text { Água } \\
\text { Metanol }\end{array}$ & $\begin{array}{l}93,5 \pm 3,2 \\
91,1 \pm 0,5 \\
60,6 \pm 1,2\end{array}$ & $\begin{array}{l}200 \\
200 \\
200\end{array}$ & $\begin{array}{l}14 \\
14 \\
14\end{array}$ \\
\hline \multicolumn{7}{|l|}{ Lardizabalaceae } \\
\hline Stauntonia obovatifoliola & Caule & ác.16ß-hidroxi-2,3-seco-lup-20(29)-ene-2,3-dioico, 37 (Triterpenoide) & Água/ etanol & 50 & 8,70 & 78 \\
\hline Stauntonia obovatifoliola & Caule & ác.16ß-hidroxi -30-noroleana-12,20(29)-dien-28-oico, 38 (Triterpenoide) & Água/ etanol & 50 & 35,0 & 78 \\
\hline Stauntonia obovatifoliola & Caule & ác. $3 \alpha, 24$-diidroxi-30-noroleana-12,20(29)-dien-28-oico, 39 (Triterpenoide) & Água/ etanol & 50 & 40,8 & 78 \\
\hline Stauntonia obovatifoliola & Caule & Resinona, $\mathbf{4 0}$ (Triterpenoide) & Água/ etanol & 50 & 29,4 & 78 \\
\hline Stauntonia obovatifoliola & Caule & 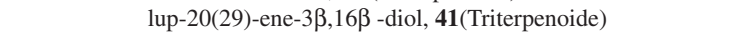 & Água/ etanol & 50 & 33,0 & 78 \\
\hline Stauntonia obovatifoliola & Caule & lup-20(29)-ene-3ß,28-diol, 42 (betulin) (Triterpenoide) & Água/ etanol & 50 & 53,0 & 78 \\
\hline Stauntonia obovatifoliola & Caule & ác. 3-O-acetiloleanolico, 43 (Triterpenoide) & Água/ etanol & 50 & 30,0 & 78 \\
\hline Stauntonia obovatifoliola & Caule & ác. mesenbriantemoidgenico, 44 (Triterpenoide) & Água/ etanol & 50 & 28,0 & 78 \\
\hline Stauntonia obovatifoliola & Caule & ác. 3ß,23-diidroxi-olean-12-en-28-oico, 45 (Triterpenoide) & Água/ etanol & 50 & 36,0 & 78 \\
\hline Stauntonia obovatifoliola & Caule & $16 \beta$-hidroxilupano-1,20(29)-dien-3-one, 46(Triterpenoide) & Água/ etanol & 50 & 25,0 & 78 \\
\hline \multicolumn{7}{|l|}{ Lauraceae } \\
\hline Lindera strychnifolia & Raiz & - & Metanol & $84,1 \pm 0,4$ & 200 & 14 \\
\hline \multicolumn{7}{|l|}{ Oleaceae } \\
\hline \multicolumn{7}{|l|}{ Paeoniaceae } \\
\hline Paeonica suffruticosa & Raiz & - & Metanol & $91,2 \pm 1$ & 200 & 14 \\
\hline \multicolumn{6}{|l|}{ Ranunculaceae } & 14 \\
\hline \multicolumn{3}{|l|}{ Rubiaceae } & Água & $80,8 \pm 1,8$ & 200 & 14 \\
\hline \multicolumn{6}{|l|}{ Sapindaceae } & 50 \\
\hline \multicolumn{7}{|l|}{ Saururaceae } \\
\hline Saururus chinensis Bail & Rizoma & Manassantina A, 47 (Lignoide) & Metanol & 50 & $38,9 *$ & 79 \\
\hline Saururus chinensis Bail & Rizoma & Saururina B, 48 (Lignoide) & Metanol & 50 & $5,60 *$ & 79 \\
\hline \multicolumn{7}{|l|}{ Sterculiaceae } \\
\hline Waltheria indica $L$ & Ramos & - & Água & 50 & 48 & 50 \\
\hline \multicolumn{7}{|l|}{ Verbenaceae } \\
\hline Aegiphila anômala & Folhas & - & Água & 50 & 87 & 50 \\
\hline \multicolumn{7}{|l|}{ Zingiberaceae } \\
\hline Boesenbergia pandurata & Rizomas & Panduratina A, 49 (Chalcona) & - & 50 & $18,7 \pm 0,8$ & 80 \\
\hline Boesenbergia pandurata & Rizomas & Hidroxipanduratina A, $\mathbf{5 0}$ (Chalcona) & - & 50 & $5,6 \pm 0,7$ & 80 \\
\hline
\end{tabular}

*Concentração em $\mu \mathrm{M}$ 
Tabela 5. Plantas e seus constituintes que apresentam atividade inibitória da replicação do HIV em cultivo celular

\begin{tabular}{|c|c|c|c|c|c|c|}
\hline $\begin{array}{l}\text { Planta testada } \\
\text { Família / Espécie }\end{array}$ & Parte utilizada & Substância isolada & Solvente & \% de inibição ${ }^{\mathrm{a}}$ & Concentração $(\mu \mathrm{g} / \mathrm{mL})$ & Ref. \\
\hline \multicolumn{7}{|l|}{ Amaryllidaceae } \\
\hline Galanthus nivalis & Bulbo & Lectina GNA (Proteína) & - & 50 & $0,33 \pm 0,15$ & 81 \\
\hline Hippeastrum hybrid & Bulbo & Lectina HHA (Proteína) & - & 50 & $0,30 \pm 0,1$ & 81 \\
\hline \multicolumn{7}{|l|}{ Anacardiaceae } \\
\hline Rhus chinensis & Caule & - & Éter de petróleo & 50 & 0,7 & 64 \\
\hline Rhus chinensis & Caule & - & Acetato de etila & 50 & 26,9 & 64 \\
\hline Rhus chinensis & Caule & - & Butanol & 50 & 17,4 & 64 \\
\hline \multicolumn{7}{|l|}{ Annonaceae } \\
\hline Desmos spp. & - & Lavinal, 51 (Flavanona) & - & 50 & 2,30 & 82 \\
\hline Desmos spp. & - & Desmetoxiateucinol, 52 (Flavanona) & - & 50 & 4,97 & 82 \\
\hline Desmos spp. & - & Desmosflavanona II, $\mathbf{5 3}$ (Flavanona) & - & 50 & 11,0 & 82 \\
\hline Desmos spp. & - & $\begin{array}{l}\text { 2-Metoxi-3-metil-4,6-diidroxi-5-(30-hidroxi) } \\
\text { cinamoilbenzaldeído, } \mathbf{5 4} \text { (Chalcona) }\end{array}$ & - & 50 & 0,022 & 82 \\
\hline \multicolumn{7}{|l|}{ Apiaceae } \\
\hline Lomatium suksdorfii & Fruto & Suksdorfina, 55 (Piranocumarina) & - & 50 & $2,6 \pm 2,1 *$ & 83 \\
\hline \multicolumn{7}{|l|}{ Asteraceae } \\
\hline Aspilia pluriseta & Folhas & - & Etanol & 50 & 16,13 & 84 \\
\hline Tithonia diversifolia & Folhas & - & Água & 50 & 0,04 & 84 \\
\hline \multicolumn{7}{|l|}{ Boranginaceae } \\
\hline Cordia spinescens & Folhas & - & Água & 50 & 15,5 & 50 \\
\hline \multicolumn{7}{|l|}{ Cactaceae } \\
\hline Pereskia bleo & Toda a planta & - & Água & 50 & 100 & 50 \\
\hline \multicolumn{7}{|l|}{ Caryophyllaceae } \\
\hline Drymaria diandra & Toda a planta & Drimaritina, 56 (Alcaloide) & Água & 50 & 0,699 & 85 \\
\hline Drymaria diandra & Toda a planta & Diandraflavona A, 57 (Flavona) & Água & 50 & 10 & 85 \\
\hline \multicolumn{7}{|l|}{ Celastraceae } \\
\hline Elaeodendron transvaalense & Raiz & - & Etanol & 50 & $0,01 * *$ & 71 \\
\hline Tripterygium hypoglaucum & Casca da Raiz & Triptonina A, $\mathbf{5 8}$ (Sesquiterpeno) & Metanol & 50 & 2,54 & 86 \\
\hline Tripterygium hypoglaucum & Casca da Raiz & Triptonina B, 59 (Sesquiterpeno) & Metanol & 50 & 0,10 & 86 \\
\hline Tripterygium wilfordii & - & Neotripterifordina, 60 (Diterpeno) & Etanol & 50 & $0,025^{*}$ & 87 \\
\hline Tripterygium wilfordii & - & Tripterifordina, 61 (Diterpeno) & Etanol & 50 & $3 *$ & 87 \\
\hline \multicolumn{7}{|l|}{ Clusiaceae } \\
\hline Calophyllum teysmannii & Casca do caule & Calanolídeo F, 62 (Dipiranocumarina) & - & 50 & $2,84 \pm 1,35^{*}$ & 88 \\
\hline Calophyllum inophyllum & Folhas e galhos & Inófilo B, 12 (Dipiranocumarina) & - & 50 & $1,4^{*}$ & 44 \\
\hline Calophyllum inophyllum & Folhas e galhos & Inófilo P, 13 (Dipiranocumarina) & - & 50 & $1,6^{*}$ & 44 \\
\hline Hypericum chinense $L$. & Folhas & Biyouyanagina A, 63 (Sesquiterpenoide) & Metanol & 50 & 0,798 & 89 \\
\hline Vismia cayennensis & Folhas & Vismiafenona D, 64(Benzofenona prenilada) & $\mathrm{MeOtBu}$ & 50 & 11 & 90 \\
\hline Combretaceae & & & & & & \\
\hline Terminalia sericea & Raiz & - & Etanol & 50 & $0,6^{* *}$ & 71 \\
\hline Compositae & & & & & & \\
\hline Baccharis trinervis & Partes aéreas & - & Água & 50 & 38 & 50 \\
\hline Bidens pilosa $\mathrm{L}$. & Partes aéreas & - & Água & 50 & 54 & 50 \\
\hline Calea jamaicensis & Raízes & - & Água & 50 & 62 & 50 \\
\hline Cucurbitaceae & & & & & & \\
\hline Hemsleya jinfushanensis & Tubérculos & Hemslecina A, 22 (Triterpenoide) & Etanol & 50 & 3,09 & 61 \\
\hline Hemsleya jinfushanensis & Tubérculos & Hemslecina B, $\mathbf{2 3}$ (Triterpenoide) & Etanol & 50 & 2,53 & 61 \\
\hline Momordica charantia $L$. & Raiz & Kuguacina C, 25 (Cucurbitacina) & Metanol & 50 & 8,45 & 91 \\
\hline Momordica charantia L. & Raiz & Kuguacina E, 26 (Cucurbitacina) & Metanol & 50 & 25,62 & 91 \\
\hline Dipterocarpaceae & & & & & & \\
\hline Hopea malibato Foxw & Folhas & Dibalanocarpol, 65 (Derivado do estilbeno) & Acetato de etila & 50 & 46 & 92 \\
\hline Hopea malibato Foxw & Folhas & Balanocarpol, 66 (Derivado do estilbeno) & Acetato de etila & 50 & 20 & 92 \\
\hline Euforbiaceae & & & & & & \\
\hline Alchornea cordifolia & Sementes & - & Água & 50 & 0,02 & 39 \\
\hline Alchornea cordifolia & Fruto & - & Água & 50 & 0,01 & 39 \\
\hline Elaeophorbia drupifera & Folhas & - & Água & 50 & 0,014 & 39 \\
\hline Jatropha curcas L. & Galhos & - & Água & 50 & 24 & 50 \\
\hline Jatropha curcas L. & Folhas & - & Metanol & 50 & 9 & 50 \\
\hline Gesneriaceae & & & & & & \\
\hline Drymonia serrulata & Folhas & - & Água & 50 & 130 & 50 \\
\hline Lamiaceae & & & & & & \\
\hline Ocimum gratissimum & Folhas & - & Água & 50 & 0,01 & 39 \\
\hline Hyssop officinalis & Folhas & Polissacarídeo MAR-10 & Água & 50 & 5 & 93 \\
\hline Leitneriaceae & & & & & & \\
\hline Leitneria floridana & Partes aéreas & 1-metoxicantinona 67 (Alcaloide) & Clorofórmio & 50 & 0.256 & 94 \\
\hline Myrtaceae & & & & & & \\
\hline Syzigium claviflorum & Folhas & Ác. betulínico, 2 (Triterpeno) & Metanol & 50 & $1,4^{*}$ & 16 \\
\hline Syzigium claviflorum & Folhas & Ác. platânico, 1 (Triterpeno) & Metanol & 50 & $13^{*}$ & 16 \\
\hline Moraceae & & & & & & \\
\hline Ficus polita & Folhas & - & Água & 50 & 0,03 & 39 \\
\hline Maclura tinctoria (L.) Steud & Casca & Macluraxantona B, 68 (Xantona prenilada) & Diclorometano-metanol & 50 & $1-2$ & 95 \\
\hline Maclura tinctoria (L.) Steud & Casca & Macluraxantona C, 69 (Xantona prenilada) & Diclorometano-metanol & 50 & $1,3-2,2$ & 95 \\
\hline Maclura tinctoria (L.) Steud & Casca & Isociclomulberrina, $\mathbf{7 0}$ (Flavona isoprenilada) & Diclorometano-metanol & 50 & 5,5 & 95 \\
\hline
\end{tabular}


Tabela 5. Continuação

\begin{tabular}{|c|c|c|c|c|c|c|}
\hline $\begin{array}{l}\text { Planta testada } \\
\text { Família / Espécie }\end{array}$ & Parte utilizada & Substância isolada & Solvente & $\%$ de inibiçãa ${ }^{a}$ & Concentração $(\mu \mathrm{g} / \mathrm{mL})$ & Ref. \\
\hline $\begin{array}{l}\text { Polygonaceae } \\
\text { Rumex bequaertii }\end{array}$ & Folhas & - & Etanol & 50 & 17,695 & 84 \\
\hline $\begin{array}{l}\text { Rubiaceae } \\
\text { Palicourea condensata }\end{array}$ & Casca do caule & Palicoureina, 28 (Peptídeo) & - & 50 & $1,5^{*}$ & 96 \\
\hline $\begin{array}{l}\text { Rutaceae } \\
\text { Clausena anisata } \\
\text { Zanthoxylum davyi }\end{array}$ & $\begin{array}{l}\text { Folhas } \\
\text { Raiz }\end{array}$ & - & $\begin{array}{l}\text { Água } \\
\text { Etanol }\end{array}$ & $\begin{array}{l}50 \\
50\end{array}$ & $\begin{array}{l}0,7 \\
1 * *\end{array}$ & $\begin{array}{l}39 \\
71\end{array}$ \\
\hline $\begin{array}{l}\text { Saururaceae } \\
\text { Saururus chinensis Bail } \\
\text { Saururus chinensis Bail } \\
\text { Saururus chinensis Bail }\end{array}$ & $\begin{array}{l}\text { Rizoma } \\
\text { Rizoma } \\
\text { Rizoma }\end{array}$ & $\begin{array}{l}\text { Saucerneol B, } 71 \text { (Lignoide) } \\
\text { Manassantina A, } 47 \text { (Lignoide) } \\
\text { Manassantina B, } 72 \text { (Lignoide) }\end{array}$ & $\begin{array}{l}\text { Metanol } \\
\text { Metanol } \\
\text { Metanol }\end{array}$ & $\begin{array}{l}100 \\
100 \\
100\end{array}$ & $\begin{array}{l}0,2 * \\
1,0 * \\
1,0 *\end{array}$ & $\begin{array}{l}79 \\
79 \\
79\end{array}$ \\
\hline $\begin{array}{l}\text { Schisandraceae } \\
\text { Kadsura heteroclita } \\
\text { Kadsura heteroclita } \\
\text { Kadsura heteroclita } \\
\text { Kadsura heteroclita } \\
\text { Kadsura heteroclita } \\
\text { Kadsura heteoclita } \\
\text { Kadsura heteroclita }\end{array}$ & $\begin{array}{l}\text { Caule } \\
\text { Caule } \\
\text { Caule } \\
\text { Caule } \\
\text { Caule } \\
\text { Caule } \\
\text { Caule }\end{array}$ & $\begin{array}{l}\text { Interiorina, } 21 \text { (Lignana) } \\
\text { Kadsurina, } 20 \text { (Lignana) } \\
\text { Heteroclitina F, } 73 \text { (Lignana) } \\
\text { Acetoxi oxokadsurana, } 74 \text { (Lignana) } \\
\text { Interiorina B, } 75 \text { (Lignana) } \\
\text { Quercetina, } 18 \text { (Flavonol) } \\
\text { Taxifolina, } 19 \text { (Flavonolignana) }\end{array}$ & (1) & $\begin{array}{l}50 \\
50 \\
50 \\
50 \\
50 \\
50 \\
50\end{array}$ & $\begin{array}{l}1,6 \\
17,4 \\
19,9 \\
7,5 \\
1,4 \\
5,3 \\
13,8\end{array}$ & $\begin{array}{l}51 \\
51 \\
51 \\
51 \\
51 \\
51 \\
51\end{array}$ \\
\hline $\begin{array}{l}\text { Simaroubaceae } \\
\text { Ailanthus altíssima } \\
\text { Ailanthus altíssima } \\
\text { Ailanthus altíssima } \\
\text { Ailanthus altíssima }\end{array}$ & $x^{2}$ & $\begin{array}{l}\text { Shinjulactona B, } 76 \text { (Quassinoide) } \\
\text { Shinjulactona C, } 77 \text { (Quassinoide) } \\
\text { Shinjudilactona, } 78 \text { (Quassinoide) } \\
\text { Ailantinol A, } 79 \text { (Quassinoide) }\end{array}$ & $x^{2}$ & $\begin{array}{l}50 \\
50 \\
50 \\
50\end{array}$ & $\begin{array}{l}28 \\
10,6 \\
43 \\
30\end{array}$ & $\begin{array}{l}52 \\
52 \\
52 \\
52\end{array}$ \\
\hline $\begin{array}{l}\text { Symplocaceae } \\
\text { Symplocos setchuensis Brand } \\
\text { Symplocos setchuensis Brand }\end{array}$ & $\begin{array}{l}\text { Caule } \\
\text { Caule }\end{array}$ & $\begin{array}{l}\text { Matairesinol, } 80 \text { (Lignana) } \\
\text { Harman, } 81 \text { (Lignana) }\end{array}$ & Clorofórmio & $\begin{array}{l}50 \\
50\end{array}$ & $\begin{array}{l}2,0 * \\
10,7 *\end{array}$ & $\begin{array}{l}97 \\
97\end{array}$ \\
\hline $\begin{array}{l}\text { Umbelliferae } \\
\text { Ferula sumbul } \\
\text { Ferula sumbul } \\
\text { Ferula sumbul } \\
\text { Ferula sumbul } \\
\text { Ferula sumbul }\end{array}$ & $\begin{array}{l}\text { Raiz } \\
\text { Raiz } \\
\text { Raiz } \\
\text { Raiz } \\
\text { Raiz }\end{array}$ & $\begin{array}{l}\text { Heraclenol, } 82 \text { (Cumarina) } \\
\text { Oxipeucedanina, } 83 \text { (Cumarina) } \\
\text { Heraclenina, } 84 \text { (Cumarina) } \\
\text { Imperatorina, } 85 \text { (Cumarina) } \\
\text { Osthol, } 86 \text { (Cumarina) }\end{array}$ & $\begin{array}{l}\text { Metanol } \\
\text { Metanol } \\
\text { Metanol } \\
\text { Metanol } \\
\text { Metanol }\end{array}$ & $\begin{array}{l}50 \\
50 \\
50 \\
50 \\
50\end{array}$ & $\begin{array}{l}0,115 \\
1,05 \\
2,37 \\
<0.10 \\
0.155\end{array}$ & $\begin{array}{l}98 \\
98 \\
98 \\
98 \\
98\end{array}$ \\
\hline $\begin{array}{l}\text { Verbenaceae } \\
\text { Cornutia grandifolia }\end{array}$ & Tronco & - & Água & 50 & 55 & 50 \\
\hline
\end{tabular}

*Concentração em $\mu \mathrm{M}$; ** Concentração em ng/mL
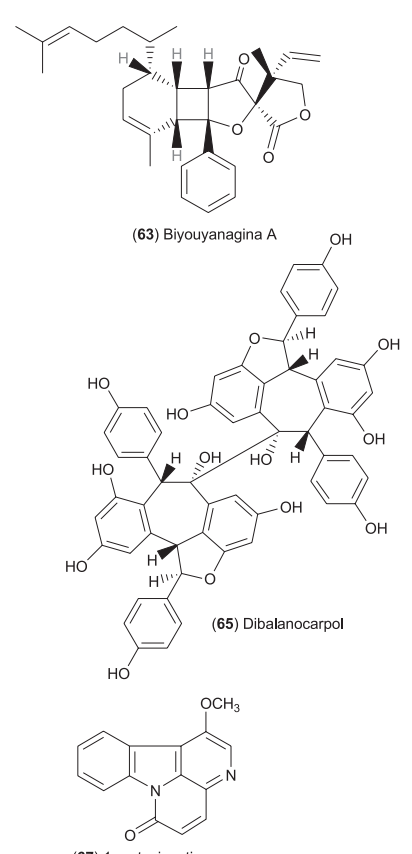

(67) 1-metoxicantinona

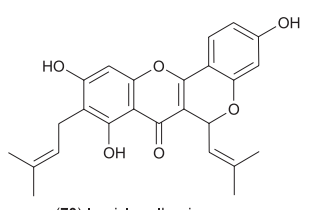

(70) Isociclomulberrina
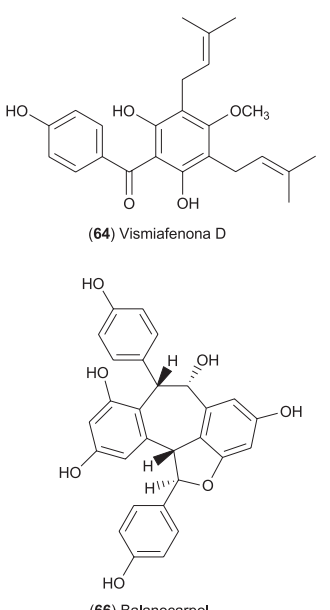

(66) Balanocarpol

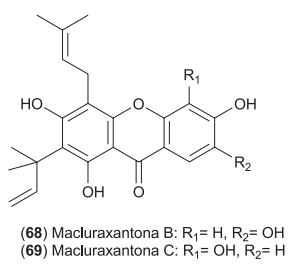

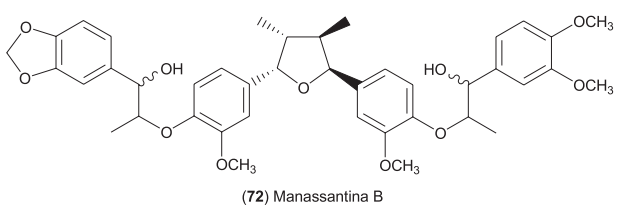
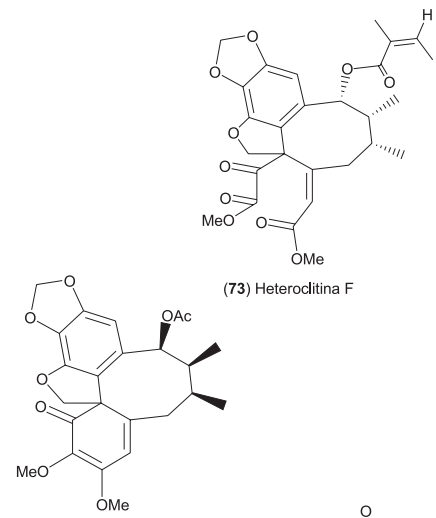

(74) Acetoxi oxokadsurana (73) Heteroclitina F

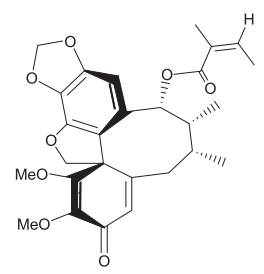

(75) Interiorina B

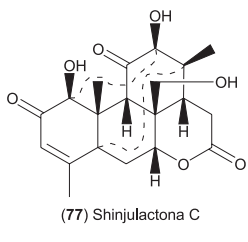

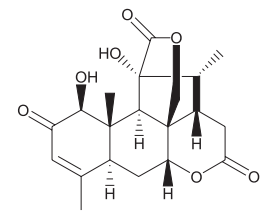

(78) Shinjudilactona

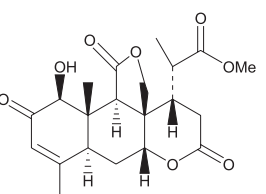

(79) Ailantinol A 


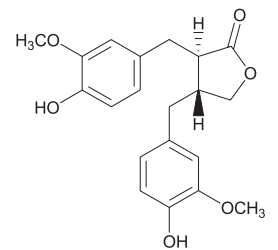

(80) Matairesinol

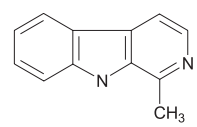

(81) Harman
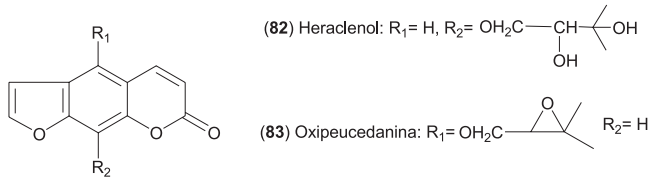

(84) Heraclenina: $\mathrm{R}_{1}=\mathrm{H}, \mathrm{R}_{2}=\mathrm{OH}_{2} \mathrm{C}$

(85) Imperatorina: $\mathrm{R}_{1}=\mathrm{H}, \mathrm{R}_{2}=\mathrm{OH}_{2} \mathrm{C}-\mathrm{C}=$

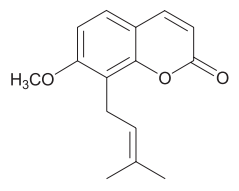

(86) Osthol

mas previne a reativação do HIV-1 em células T. Em adição, a denbinobina (16) inibe a atividade do HIV-1-LTR durante a transcrição e elongação. ${ }^{57}$

Nas diferentes plantas pesquisadas é muito grande a variedade de compostos isolados com ação anti-HIV, tendo sido encontradas substâncias de várias classes, ${ }^{57}$ como taninos (geraniina, $\mathbf{8}$ e corilagina, 9); flavonoides (baicalina, 14 catequina,17; quercetina, 18), lignanas (taxifolina, 19; kadsurina, 20; interiorina, 21), terpenoides (hemslecina A, 22 e B, 23; ác. ursólico, 24; kuguacinas C, 25 e E, 26; ác. betulínico (2) e derivados), cumarinas (calanolídeos A, 4, e B, 10; inófilos B 12,e P, 13; e soulatrolídeo, 11), proteínas e peptídeos (lectina, contrajervina, 27 e palicoureina, 28) (Tabelas 1-5). Dentre as catequinas pode-se destacar o galato de epigalocatequina (EGCG) (29), isolado do chá verde, que impede a ligação da glicoproteína 120 do HIV-1 na molécula CD4, inibindo assim a infectividade viral. O galato de epigalocatequina EGCG (29) está sendo investigado como uma alternativa natural para a terapia anti-HIV. ${ }^{58,59}$

\section{CONCLUSÃO}

Recentes avanços na definição dos mecanismos de ação de inúmeros produtos naturais derivados de plantas têm ressaltado o potencial destes no desenvolvimento de terapias antivirais. ${ }^{8}$ Vários produtos naturais estão sendo testados visando uma alternativa na terapia contra o HIV, alguns dos quais já apresentaram comprovada eficácia clínica, atuando inclusive contra cepas resistentes aos antirretrovirais tradicionais. Contudo, faz-se necessário ampliar o leque de alternativas terapêuticas, buscando sempre novos princípios ativos eficientes na terapia antirretroviral, dada a grande mutagenicidade destes vírus. Além disso, como vimos, as plantas são uma grande fonte de substâncias para desenvolvimento de novos medicamentos, devendo sempre ser investigadas.

\section{AGRADECIMENTOS}

Aos órgãos financiadores CNPq, CAPES, FAPEAL e RENOR$\mathrm{BIO}$, pelo suporte financeiro às pesquisas.

\section{REFERÊNCIAS}

1. Vaishnav, Y. N.; Wong-Staal, F.; Annu. Rev. Biochem. 1991, 60, 577.

2. Campbell, R. S. F. C.; Robinson, W. F.; J. Comp. Path. 1998, 119, 333.

3. http://www.unaids.org/en/KnowledgeCentre/HIVData/ GlobalReport/2008/, acessada em Fevereiro 2009.

4. Brasil, Ministério da Saúde, Boletim Epidemiológico - AIDS e DST, 2008, disponível em http://www.aids.gov.br, acessada em Agosto 2009.

5. Adamson, C. S.; Freed, E. O.; Drug Discov. Today 2008, 13, 424.

6. Lüllmann, H.; Ziegler, A.; Mohr, K.; Bieger, D.; Color Atlas of Pharmacology, $2^{\text {nd }}$ ed., Thieme: New York, 2000.

7. Hardman, J. G.; Limbird, L. E.; Gilman, A. G.; Goodman \& Gilman. As bases farmacológicas da terapêutica, $10^{\text {th }}$ ed., McGraw-Hill: Rio de Janeiro, 2005.

8. Aiken, C.; Chen, C. H.; Trends Mol. Med. 2005, 11, 31.

9. Brasil, Ministério da Saúde, Secretária de Vigilância em Saúde, Programa Nacional de DST e Aids; Recomendações para Terapia Antiretroviral em Adultos Infectados pelo HIV: 2008, 7 ${ }^{\text {a }}$ ed.; 2008/Consenso: Recomendações para Terapia Antirretroviral em Adultos Infectados pelo HIV - 2008 - Suplemento No 01/Recomendações para Terapia Antirretroviral em Crianças e Adolescentes Infectados pelo HIV, 2009.

10. Turriziani, O.; Antonelli, G.; Dianzani, F.; Int. J. Antimicrob. Agents 2000, 16, 353; Ren, J.; Nichols, C.; Bird, L.; Chamberlain, P.; Weaver, K.; Short, S.; Stuart, D. I.; Stammers, D. K.; J. Mol. Biol. 2001, 312, 795; Margot, N. A.; Waters, J. M.; Miller, M. D.; Antimicrob. Agents Chemother. 2006, 50, 4087.

11. De Aragão, P. A.; Lemos, R. B. P.; Aquino, M. Z.; Marques, H. H. S.; Braz. J. Infect. Dis. 2002, 6, 142; Jaime, P. C.; Florindo, A. A.; Latorre, M. R. D. O.; Brasil, B. G.; Dos Santos, E. C. M.; Segurado, A. A. C.; Rev. Bras. Epidemiol. 2004, 7, 65; De Oliveira, A. M.; Costa, L. F.; Da Fonseca, C. A.; Rev. Elet. Farm. 2006, 3, 31.

12. Cos, P.; Maes, L.; Berghe, D. V.; Hermans, N.; Pieters, L.; Vlietinck, A. J.; J. Nat. Prod. 2004, 67, 284.

13. Calderone, V.; Nicoletti, E.; Bandecchi, P.; Pistello, M.; Mazzetti, P.; Martinotti, E.; Morelli, I.; Phytotherapy Res. 1998, 12, 595; Chang, R. S.; Yeung, H. W.; Antiviral Res. 1988, 9, 163; Bedoya, L. M.; Álvarez, A.; Bermejo, M.; González, N.; Beltrán, M.; Sanchez-Palomino, S.; Cruz, S. M.; Gaitán, I.; Del Olmo, E.; Escarcena, R.; Garcia, P. A.; Cáceres, A.; San Feliciano, A.; Alcami, J.; Phytomedicine 2008, 15, 520; Cos, P.; Maes, L.; Vlietinck, A.; Pieters, L.; Planta Med. 2008, 74, 1323; Kostova, I.; Curr. HIV Res. 2006, 4, 347.

14. Lam, T. L.; Lam, M. L.; Au, T. K.; Ip, D. T. M.; Ng, T. B.; Fong, W. P.; Wan, D. C. C.; Life Sci. 2000, 67, 2889.

15. Manganelli, R. E.; Zaccaro, L.; Tomei, P. E.; J. Ethnopharmacol. 2005, 98, 323.

16. Fujioka, T.; Kashiwada, Y.; Kilkuskie, R. E.; Cosentino, L. M.; Ballas, L. M.; Jiang, J. B.; Janzen, W. P.; Chen, I. S.; Lee, K. H.; J. Nat. Prod. 1994, 57, 243

17. Cunico, W.; Gomes, C. R. B.; Vellasco Junior, W. T.; Quim. Nova 2008, 31, 2111.

18. Yang, S. S.; Cragg, G. M.; Newman, D. J.; Bader, J. P.; J. Nat. Prod. 2001, 64, 265.

19. De Souza, M. V. N.; De Almeida, M. V.; Quim. Nova 2003, 26, 366.

20. Saklani, A.; Kutty., S. K.; Drug Discov. Today 2008, 13, 161.

21. Gulick, R. M.; Mcauliffe, V.; Holden-Wiltse, J.; Crumpacker, C.; Liebes, L.; Stein, D. S.; Meehan, P.; Hussey, S.; Forcht, J.; Valentine, F. T.; Ann. Internal Med. 1999, 130, 510.

22. De Albuquerque, U. P.; Hanazaki, N.; Rev. Bras. Farmacogn. 2006, 16, 678.

23. De Lima, M. R. F.; Luna, J. D.; Dos Santos, A. F.; De Andrade, M. C. C.; Sant'Ana, A. E. G.; Genet, J. P.; Marquez, B.; Neuville, L.; Moreau, N.; J. Ethnopharmacol. 2006, 105, 137; De Omena, M. C.; Navarro, D. M. A. F; De Paula, J. E.; Luna, J. S.; De Lima, M. R. F.; Sant'Ana, A. 
E. G.; Bioresour. Technol. 2007, 98, 2549; Marquez, B.; Neuville, L.; Moreau, N. J.; Genet, J. P.; Dos Santos, A. F.; De Andrade, M. C. C.; Sant'Ana, A. E. G.; Phytochemistry 2005, 66, 1804.

24. Brooks, G. F.; Butel, J. S.; Morse, S. A.; Jawetz, Melnick \& Adelberg Microbiologia Médica, 21 $1^{\text {th }}$ ed., Guanabara Koogan: Rio de Janeiro, 2000.

25. Frankel, A. D.; Young, J. A. T.; Annu. Rev. Biochem. 1998, 67, 1.

26. Clements, J. E.; Payne, S. L.; Virus Res. 1994, 32, 97.

27. Ali, A.; Realegeno, S.; Yang, O. O.; Lewis, M. J.; J. Virol. Methods 2009, 161, 297.

28. Chaudhry, A.; Verghese, D. A.; Das, S. R.; Jameel, S.; George, A.; Bal, V.; Mayor, S.; Rath, S.; J. Immunol. 2009, 183, 2415.

29. Hussain, A.; Wesley, C.; Khalid, M.; Chaudhry, A.; Jameel, S.; J. Virol. 2008, 82, 893

30. Peçanha, E. P.; Antunes, O. A. C.; Tanuri, A.; Quim. Nova 2002, 25, 1108.

31. Sierra, S.; Kupfer, B.; Kaiser, R.; J. Clin. Virol. 2005, 34, 233.

32. Yang, X.; Kurteva, S.; Ren, X.; Lee, S.; Sodroski, J.; J. Virol. 2005, 79, 12132.

33. Suzuki, Y.; Craigie, R.; Nat. Rev. Microbiol. 2007, 5, 187; Christ, F.; Thys, W.; De Rijck, J.; Gijsbers, R.; Albanese, A.; Arosio, D.; Emiliani, S.; Rain, J.; Benarous, R.; Cereseto, A.; Debyser, Z.; Curr. Biol. 2008, $18,1192$.

34. Ciuffi, A.; Bushman, F. D.; Trends Genet. 2006, 22, 388.

35. Vlietinck, A. J.; Berghe, D. A. V.; J. Ethnopharmacol. 1991, 32, 141; Tshikalange, T. E.; Meyer, J. J. M.; Lall, N.; Muñoz, E.; Sancho, R.; van de Venter, M.; Oosthuizen, V.; J. Ethnopharmacol. 2008, 119, 478.

36. Dias, K. S.; Marques, M. S.; Menezes, I. A. C.; Santos, T. C.; Silva, A. B. L.; Estevam, C. S.; Sant'Ana, A. E. G.; Pizza, C.; Antoniolli, A. R.; Marçal, R. M.; Fitoterapia 2007, 78, 460.

37. Duarte D. F. P.; Sant'Ana, A. E. G.; Calixto, J. B.; Eur. J. Pharmacol. 1992, 15, 75; Cos, P.; Vlietinck, A. J.; Berghe, D. V.; Maes, L.; J. Ethnopharmacol. 2006, 106, 290; Yunes, R. A.; Pizzolatti, M. G.; Sant'Ana, A. E. G.; Hawkes, G. E.; Calixto, J. B.; Phytochem. Anal. 1993, 4, 76.

38. Mukhtar, M.; Arshad, M.; Ahmad, M.; Pomerantz, R. J.; Wigdahl, B.; Parveen, Z.; Virus Res. 2008, 131, 111.

39. Ayisi, N. K.; Nyadedzor, C.; Antiviral Res. 2003, 58, 25.

40. Tilton, J. C.; Doms, R. W.; Antiviral Res. 2010, 85, 91.

41. Bedoya, L. M.; Marquez, N.; Martinez, N.; Gutierrez-Eisman, S.; Aluarez, A.; Calzado, M. A.; Rojas, J. M.; Appendino, G.; Munoz, E.; Alcami, J.; Biochem. Pharmacol. 2009, 77, 965.

42. Notka, F.; Meier, G.; Wagner, R.; Antiviral Res. 2004, 64, 93.

43. Wang, L. Z.; Kenyon, G. L.; Johnson, K. A.; J. Biol. Chem. 2004, 279, 38424.

44. Patil, A. K.; Freyer, A. J.; Eggleston, D. S.; Haltiwanger, R. C.; Bean, M. F.; Taylor, P. B.; Caranfa, M. J.; Breen, A. L.; Bartus, H. R.; Johnson, R. K.; Hertzberg, R. P.; Westley, J. W.; J. Med. Chem. 1993, 36, 4131.

45. De Melo, E. B.; Bruni, A. T.; Ferreira, M. M. C.; Quim. Nova 2006, 29, 555.

46. Reinke, R. A.; Lee, D. J.; McDougall, B. R.; King, P. J.; Victoria, J.; Mao, Y.; Lei, X.; Reinecke, M. G.; Robinson Jr, W. E.; Virology 2004, 326, 203.

47. Gray, D. E.; Roberts, C. A.; Rottinghaus, G. E.; Garrett, H. E.; Pallardy, S. G.; Crop Sci. 2001, 41,1159.

48. Bessong, P. O.; Obi, C. L.; Andréola, M.; Rojas, L. B.; Pouysegu, L.; Igumbor, E.; Meyer, J. J. M.; Quideau, S.; Litvak, S.; J. Ethnopharmacol. 2005, 99, 83.

49. Wang, X.; Morris-Natschke, S. L.; Lee, K. H.; Med. Res. Rev. 2007, 27, 133.

50. Matsuse, I. T.; Lim, Y. A.; Hattori, M.; Correa, M.; Gupta, M. P.; J. Ethnopharmacol. 1999, 64, 15.

51. Pu, J.; Yang, L.; Xiao, W.; Li, R.; Lei, C.; Gao, X.; Huang, S.; Li, S.; Zheng, Y.; Huang, H.; Sun, H.; Phytochemistry 2008, 69, 1266.
52. Okano, M.; Fukamiya, N.; Tagahara, K.; Cosentino, M.; Lee, T. T.; Morris-Natschke, S.; Lee, K.; Bioorg. Med. Chem. Lett. 1996, 6, 701.

53. Bedoya, L. M.; Sanchez-Palomino, S.; Abad, M.J.; Bermejo, P.; Alcami, J.; J. Ethnopharmacol. 2001, 77, 113.

54. Smith, P. F.; Ogundele, A.; Forrest, A.; Wilton, J.; Salzwedel, K.; Doto, J.; Allaway, G. P.; Martin, D. E.; Antimicrob. Agents Chemother. 2007, 51,3574 .

55. Li, F.; Goila-Gaur, R.; Salzwedel, K.; Kilgore, N. R.; Reddick, M.; Matallana, C.; Castillo, A.; Zoumplis, D.; Martin, D. E.; Orenstein, J. M.; Allaway, G. P.; Freed, E. O.; Wild, C. T.; Proc. Natl. Acad. Sci. 2003, 100, 13555.

56. Itokawa, H.; Morris-Natschke, S. L.; Akiyama, T.; Lee, K. H.; J. Nat. Med. 2008, 62, 263.

57. Sánchez-Duffhues, G.; Calzado, M. A.; Vinuesa, A. G.; Caballero, F. J.; Ech-Chahad, A.; Appendino, G.; Krohn, K.; Fiebich, B. L.; Muñoz, E.; Biochem. Pharmacol. 2008, 76, 1240.

58. Williamson, M. P.; McCormick, T. G.; Nance, C. L.; Shearer, W. T.; J. Allergy Clin. Immunol. 2006, 118, 1369.

59. Nance, C. L.; Siwak, E. B.; Shearer, W. T.; J. Allergy Clin. Immunol. 2009,123, 459 .

60. Bedoya, L. M.; Abad, M. J.; Sánchez-Palomino, S.; Alcami, J.; Bermejo, P.; Phytomedicine 2010, 17, 69.

61. Tian, R. R.; Chen, J. C.; Zhang, G. H.; Qiu, M. H.; Wang, Y. H.; Du, L.; Shen, X.; Liu, N. F.; Zheng, Y. T.; Chin. J. Nat. Med. 2008, 6, 214.

62. Bokesch, H. R.; Charan, R. D.; Meragelman, K. M.; Beutler, J. A.; Gardella, R.; O'Keefe, B. R.; McKee, T. C.; McMahon, J. B.; FEBS Lett. 2004, 567, 287.

63. Chang, Y. S.; Woo, E. R.; Phytother. Res. 2003, 17, 426.

64. Wang, R.; Gu, Q.; Yang, L.; Chen, J.; Li, S.; Zheng, Y.; J. Ethnopharmacol. 2006, 105, 269.

65. Woradulayapinij, W.; Soonthornchareonnon, N.; Wiwat, C.; J. Ethnopharmacol. 2005, 101, 84.

66. Klos, M.; van de Venter, M.; Milne, P. J.; Traore, H. N.; Meyer, D.; Oosthuizen, V.; J. Ethnopharmacol. 2009, 124, 182.

67. Harnett, S. M.; Oosthuizen, V.; van de Venter, M.; J. Ethnopharmacol. 2005, 96, 113.

68. Lam, S.-K.; Ng, T.-B.; Phytomedicine 2009, 16, 444.

69. Huerta-Reyes, M.; Basualdo, M. C.; Abe, F.; Jimenez-Estrada, M.; Soler, C.; Reyes-Chilpa, R.; Biol. Pharm. Bull. 2004, 27, 1471.

70. Ali, H.; König, G. M.; Khalid, S. A.; Wright, A. D.; Kaminsky, R.; J. Ethnopharmacol. 2002, 83, 219.

71. Tshikalange, T. E.; Meyer, J. J.; Hattori, T.; Suzuki, Y. S.; Afric. J. Botany 2008, 74, 391.

72. Min, B. S.; Kim, Y. H.; Tomiyama, M.; Nakamura, N.; Miyashiro, H.; Otake, T.; Hattori, M.; Phytother. Res. 2001, 15, 481.

73. Fang, E. F.; Wong, J. H.; Ng, T. B.; J. Biosci. Bioeng. 2010, 109, 211.

74. Kitamura, K.; Honda, M.; Yoshizaki, H.; Yamamoto, S.; Nakane, H.; Fukushima, M.; Ono, K.; Tokunaga, T.; Antiviral Res. 1998, 37, 131.

75. Kim, H. J.; Woo, E. R.; Shin, C. G.; J. Nat. Prod., 1998, 61, 145.

76. Tewtrakul, S.; Itharat, A.; Rattanasuwan, P.; J. Ethnopharmacol. 2006, $105,312$.

77. Lee, J. S.; Miyashiro, H.; Nakamura, N.; Hattori, M.; Chem. Pharm. Bull. 2008, 56, 711.

78. Wei, Y.; Ma, C.; Chen, D.; Hattori, M.; Phytochemistry 2008, 69, 1875.

79. Lee, J. S.; Huh, M. S.; Kim, Y. C.; Hattori, M.; Otake, T.; Antiviral Res. 2010, 85, 425.

80. Cheenpracha, S.; Karalai, C.; Ponglimanont, C.; Subhadhirasakul, S.; Tewtrakul, S.; Bioorg. Med. Chem. 2006, 14, 1710.

81. Balzarini, J.; Hatse, S.; Vermeire, K.; Princen, K.; Aquaro, S.; Perno, C-F.; De Clercq, E.; Egberink, H.; van den Mooter, G.; Peumans, W.; van Damme, E.; Schols, D.; Antimicrob. Agents Chemother. 2004, 48, 3858.

82. Wu, J.; Wang, X.; Yi, Y.; Lee, K.; Bioorg. Med. Chem. Lett. 2003, 13, 1813. 
83. Lee, T. T.; Kashiwada, Y.; Huang, L.; Sneider, J.; Cosentino, M.; Lee, K. H.; Bioprog. Med. Chem. 1994, 2, 1051.

84. Cos, P.; Hermans, N.; De Bruyne, T.; Apers, S.; Sindambiwe, J. B.; Witvrouw, M.; De Clercq, E.; Berghe, D. V.; Pieters, L.; Vlietinck, A. J.; Phytomedicine 2002, 9, 62.

85. Hsieh, P. W.; Chang, F. R.; Lee, K. H.; Hwang, T. L.; Chang, S. M.; Wu, Y. C.; J. Nat. Prod. 2004, 67, 1175.

86. Duan, H.; Takaishi, Y.; Imakura, Y.; Jia, Y.; Li, D.; Cosentino, M.; Lee, K. H.; J. Nat. Prod. 2000, 63, 357.

87. Yu, D.; Morris-Natschke, S. L.; Lee, K. H.; Med. Res. Rev. 2007, 27, 108.

88. McKee, T. C.; Fuller, R. W.; Covington, C. D.; Cardellina II, J. H.; Gulakowski, R. J.; Krepps, B. L.; McMahon, J. B.; Boyd, M. R.; J. Nat. Prod. 1996, 59, 754.

89. Tanaka, N.; Okasaka, M.; Ishimaru, Y.; Takaishi, Y.; Sato, M.; Okamoto, M.; Oshikawa, T.; Ahmed, S. U.; Consentino, L. M.; Lee, K. H.; Org. Lett. 2005, 7, 2997.
90. Fuller, R. W.; Westergaard, C. K.; Collins, J. W.; Cardellina II, J. H.; Boyd, M. R.; J. Nat. Prod. 1999, 62, 67.

91. Chen, J.; Tian, R.; Qiu, M.; Lu, L.; Zheng, Y.; Zhang, Z.; Phytochemistry 2008, 69, 1043.

92. Dai, J. R.; Hallok, Y. F.; Cardellina, J. H.; J. Nat. Prod. 1998, 61, 351.

93. Gollapudi, S.; Sharma, H. A.; Aggarwal, S.; Byers, L. D.; Ensley, H. E.; Gupta, S.; Biochem. Biophys. Res. Commun. 1995, 210, 145.

94. Xu, Z.; Chang, F. R.; Wang, H. K.; Kashiwada, Y.; McPhail, A. T.; Bastow, K. F.; Tachibana, Y.; Cosentino, M.; Lee, K. H.; J. Nat. Prod. 2000, 63, 1712 .

95. Groweiss, A.; Cardellina, J. H.; Boyd, M. R.; J. Nat. Prod. 2000, 63, 1537.

96. Bokesch, H. R.; Pannell, L. K.; Cochran, P. K.; Sowder, R. C.; Mckee, T. C.; Boyd, M. R. A.; J. Nat. Prod. 2001, 64, 249.

97. Ishida, J.; Wang, H. K.; Oyama, M.; Cosentino, M. L.; Hu, C. Q.; Lee, K. H.; J. Nat. Prod. 2001, 64, 958.

98. Zhou, P.; Takaishi, Y.; Duan, H.; Phytochemistry 2000, 53, 689. 